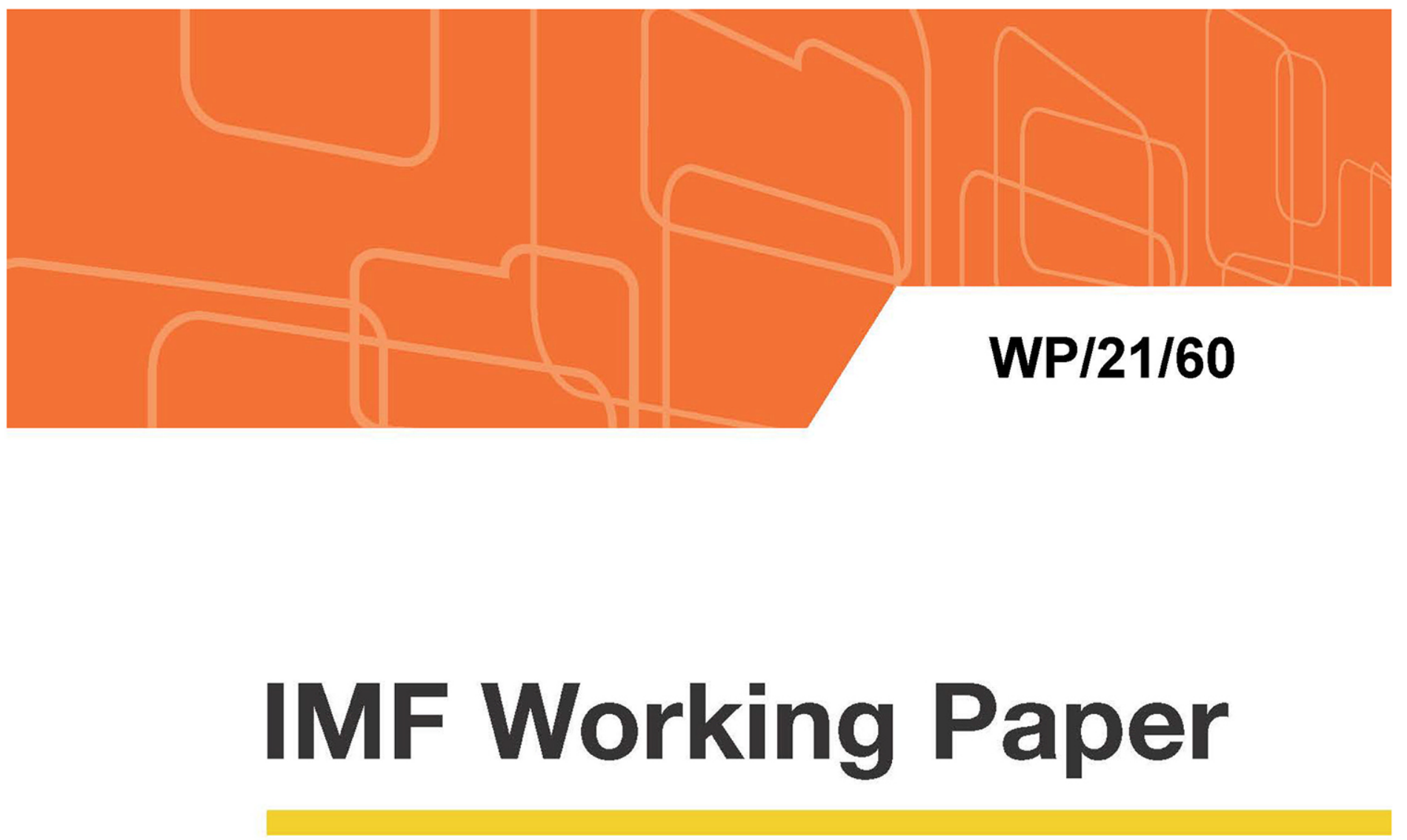

\title{
Education and Health for Inclusiveness
}

by Deon Filmer, Roberta Gatti, Halsey Rogers, Nikola Spatafora, and Drilona Emrullahu

IMF Working Papers describe research in progress by the author(s) and are published to elicit comments and to encourage debate. The views expressed in this IMF Working Paper are those of the authors and do not necessarily represent the views of the IMF, the World Bank and its affiliated organizations, their Executive Boards, or their management. 


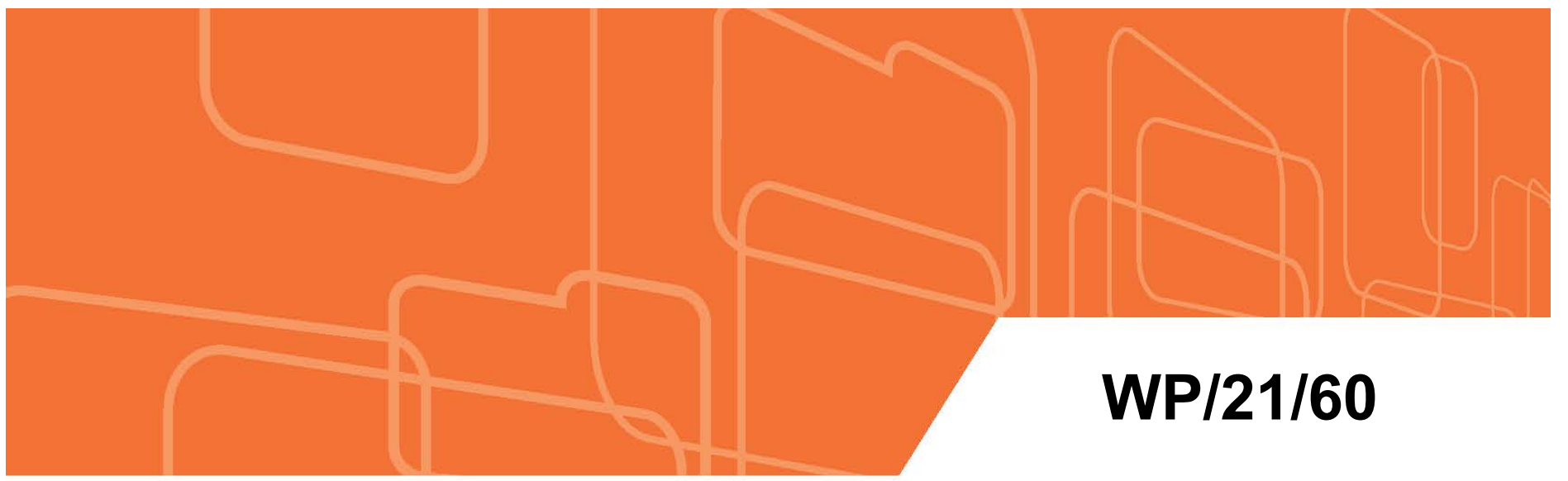

\section{IMF Working Paper}

\section{Education and Health for Inclusiveness}

by Deon Filmer, Roberta Gatti, Halsey Rogers, Nikola Spatafora, and Drilona Emrullahu

IMF Working Papers describe research in progress by the author(s) and are published to elicit comments and to encourage debate. The views expressed in this IMF Working Paper are those of the authors and do not necessarily represent the views of the IMF, the World Bank and its affiliated organizations, their Executive Boards, or their management.

I N T E R N A T I O N A L M O N E T A R Y F U N D 


\title{
IMF Working Paper
}

Institute for Capacity and Development

\section{Education and Health for Inclusiveness}

\section{Prepared by Deon Filmer, Roberta Gatti, Halsey Rogers, Nikola Spatafora, and Drilona Emrullahu ${ }^{1}$}

Authorized for distribution by Paul Cashin and Valerie Cerra

March 2021

IMF Working Papers describe research in progress by the author(s) and are published to elicit comments and to encourage debate. The views expressed in this IMF Working Paper are those of the authors and do not necessarily represent the views of the IMF, the World Bank and its affiliated organizations, their Executive Boards, or their management.

\begin{abstract}
We discuss existing shortfalls and inequalities in the accumulation of human capital—knowledge, skills, and health. We analyze their immediate and systemic causes, and assess the scope for public intervention. The broad policy goals should be to improve: the quality, and not just the quantity, of education and health care; outcomes for disadvantaged groups; and lifelong outcomes. The means to achieve these goals, while maximizing value for money, include: focusing on results rather than just inputs; moving from piecemeal interventions to systemic reform; and adopting a "whole-of-society" approach. Reforms must be underpinned by a robust evidence base.
\end{abstract}

JEL Classification Numbers: I10, I18, I20, I28.

Keywords: Education, Health, Inclusive Growth.

Authors’ E-Mail Addresses: dfilmer@worldbank.org, rgatti@worldbank.org, hrogers@,worldbank.org, nspatafora@imf.org, demrullahu@,imf.org

1 We are grateful for comments received from Andy Berg, Boele Bonthuis, Valerie Cerra, Barry Eichengreen, Mai Farid, Nicoletta Feruglio, Margaret Kruk, Samah Mazraani, Rasmane Ouedraogo, Joe Procopio, Jigyasa Sharma, Owen Smith, Damien de Walque, Jung Eun Yoon, and participants in the Inclusive Growth book seminar series organized by the IMF Institute for Capacity Development. This is a draft of a chapter accepted for publication by Oxford University Press in the forthcoming book "How to Achieve Inclusive Growth", edited by V. Cerra, B. Eichengreen, A. El-Ganainy, and M. Schindler. 


\section{Contents}

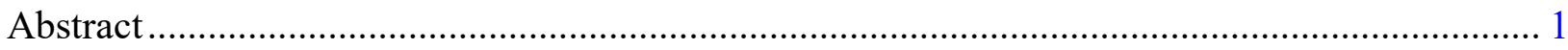

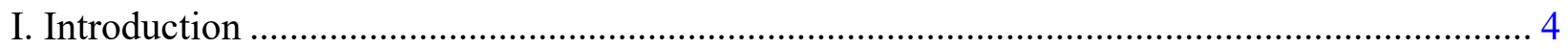

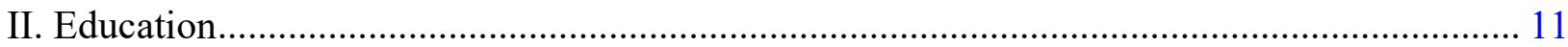

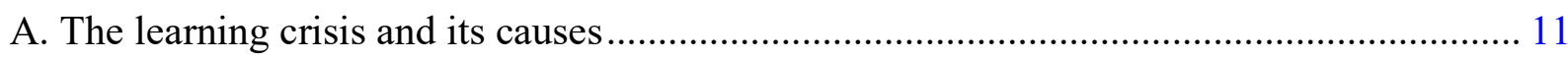

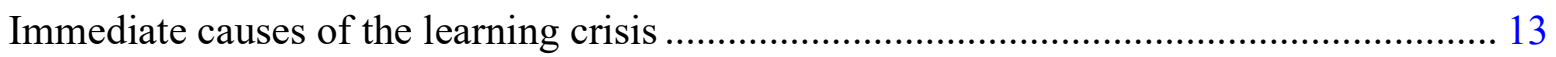

Systemic causes of the learning crisis............................................................................ 14

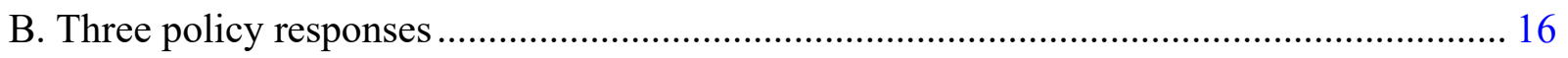

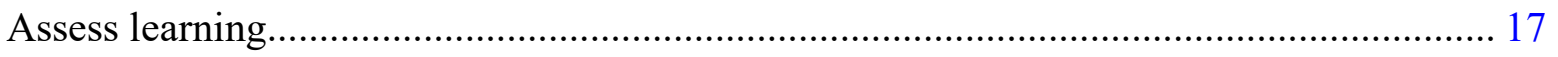

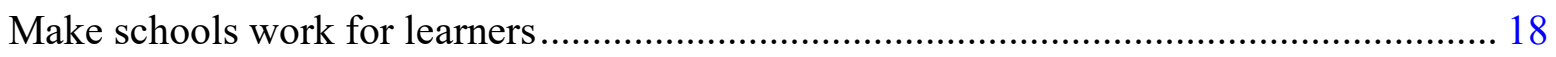

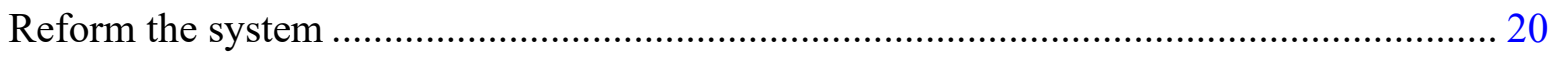

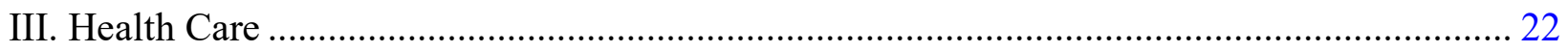

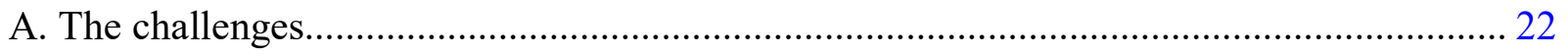

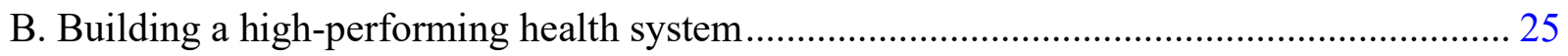

Moving away from hospital-centric structures, by increasing the availability, effectiveness,

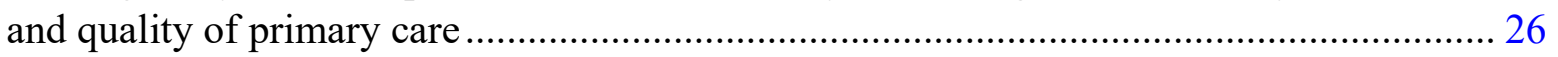

Improving quality of care in treating both chronic and acute illness................................... 27

Reforming mechanisms for paying health-care providers ................................................ 28

Improving the price and availability of critical medical products ....................................... 29

Accelerating technological transformation, while prioritizing among available interventions

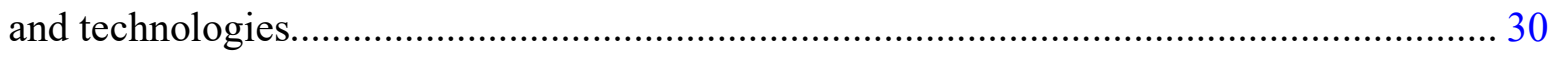

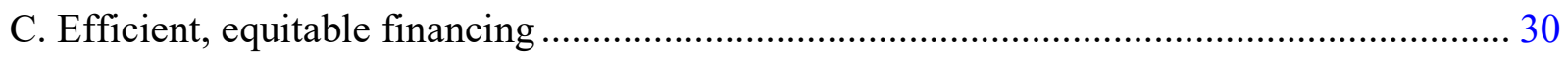

IV. Reasons for Optimism: Case Studies of Successful Reform ................................................. 32

A. Overall human-capital development ........................................................................... 32 


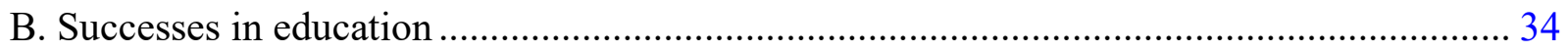

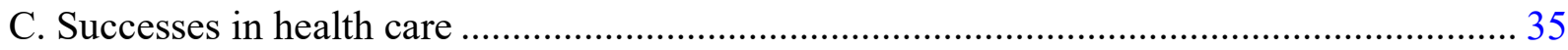

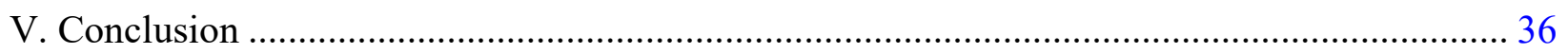

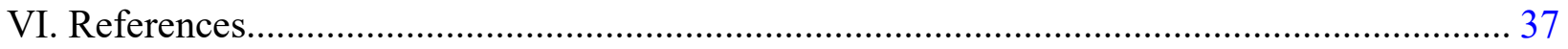


"Education then, beyond all other devices of human origin, is the great equalizer of the conditions of men, the balance-wheel of the social machinery"

—Horace Mann

"Of all the forms of inequality, injustice in health is the most shocking and inhuman"

—Martin Luther King, Jr

\section{INTRODUCTION}

Economies prosper when people are well educated and healthy, two key prerequisites for inclusive growth. Education and health, beyond their undeniable intrinsic value, enable people to realize their potential as productive members of society. More human capital-knowledge, skills, and health — leads to higher earnings for individuals, increased social mobility, and faster and more sustainable growth for countries. ${ }^{2}$ People across the world see education and health as a priority. And human capital is particularly important for disadvantaged households, who rely on it to escape deprivation. But in practice the accumulation of human capital has often become a mechanism for the perpetuation of inequality and poverty.

Substantial human-capital shortfalls and equity gaps persist. Worldwide, a child born in early 2020, just before the COVID-19 pandemic struck, could on average expect to achieve just 56 percent of her potential human capital - her productivity as a future worker were she to enjoy complete education and full health (World Bank 2020). ${ }^{3}$ Human capital increases systematically with income, both across and within countries, reflecting inequalities in the access to, quantity, and quality of education and health care. Gaps in human capital remain especially deep in lowincome countries (LICs) and those affected by institutional fragility, armed conflict, and violence. In the poorest countries, a child will on average grow up to be only about 30 percent as productive as she could be. And, within any given country, rich households accumulate greater overall human

${ }^{2}$ Flabbi and Gatti (2018) and Rossi (2019) review the literature linking human capital with earnings, income, and growth.

3 "Complete education" is defined as 14 learning-adjusted years of schooling, and "full health" as 100 percent child-survival rates and no childhood stunting. They do not imply equal productivity or outcomes across individuals. Kraay (2019) and D'Souza et al. (2019) provide details on, respectively, the construction of this human capital index and its socioeconomic disaggregation. World Bank (2020) summarizes the key messages from analyzing the index. 
capital than poor ones (Figure 1). ${ }^{4}$ Similar income gradients emerge when analyzing specific education outcomes, such as school completion rates (Figure 2), and health outcomes, including various measures of mortality and morbidity (Figure 3 and Figure 4) (see also O'Donnell et al. 2014). Some of these within-country differences by income level coincide with rural-urban or ethnic divides, further threatening social cohesion. And these opportunity gaps have displayed only a weak tendency to decrease over time.

The COVID-19 pandemic highlighted the fragility and inequity of many education and health systems. School closures and family hardship put pressure on students, teachers, and parents, and left millions at risk of dropping out of school. The disruption in health services and losses in income acted to increase child mortality and chronic malnutrition. In both cases, the impact will be felt for decades, and will prove especially severe among already disadvantaged groups.

Within-country differences across socioeconomic quintiles account for roughly one-third of the total variation in human capital in low- and middle-income economies (D'Souza et al. 2019). ${ }^{5}$ In fact, average human capital outcomes increase with income at roughly the same rate across socio-economic groups within countries as they do across countries. This suggests that national social protection and other programs aimed at mitigating human-capital risks affecting poor households are relatively ineffective - no better than the mechanisms for sharing risk across countries.

Governments have a vital role to play in reducing this inequality of opportunity. Inequalities in education and health matter intrinsically, and are likely to be transmitted across generations. These inequalities stem at least partly from barriers to investment in human capital which, by preventing the full development of individual talents, constrain overall growth (Flabbi and Gatti 2018). Intervention is further justified by important externalities and public goods - in public health and health research, but also in education, which yields positive economic and social spillovers through faster technological innovation and adoption (Huang et al. 2020), lower crime (Bell et al. 2018), a vibrant press (Guseva et al. 2008), and the creation of shared values, high levels of political engagement, trust, and tolerance (Chong and Gradstein 2015). Critically, appropriate interventions can boost both efficiency and equity; there is no inherent trade-off between these goals when addressing inequality of opportunity in education and health.

${ }^{4}$ In Madagascar, shortfalls in education and health, and their differential impact across socioeconomic groups, imply that the expected productivity as future workers of children born into the poorest and richest quintile equals, respectively, 40 percent and 58 percent of its potential level. In richer Vietnam, the corresponding values equal 58 percent and 85 percent.

${ }^{5}$ In both Madagascar and Vietnam, the within-country rich-poor gap equals roughly half the gap in average human capital between the highest- and lowest-performing country. 
Figure 1. Human Capital and Income Within and Across Countries

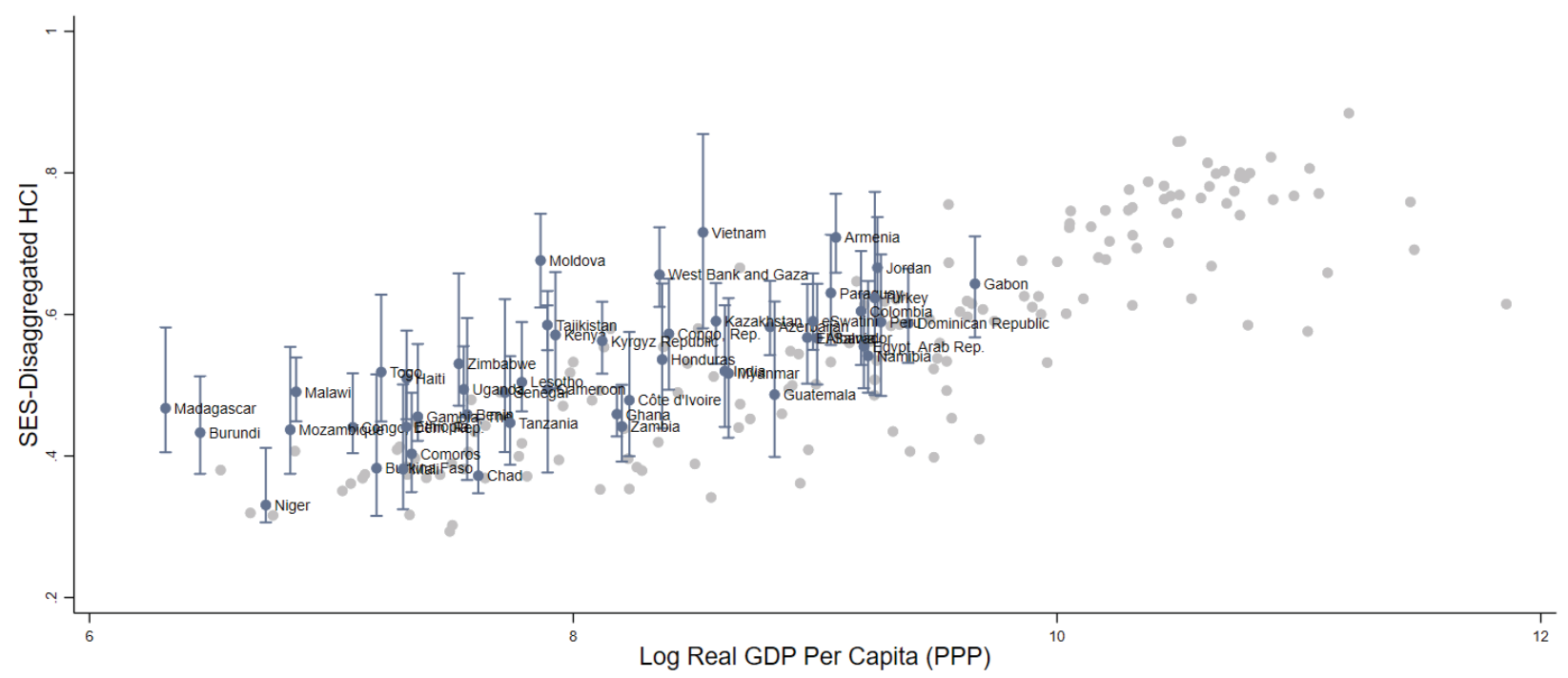

Source: D'Souza et al. (2019), figure 6. License: CC BY 3.0 IGO.

Note: The figure depicts the World Bank Human Capital Index (HCI) disaggregated by socioeconomicstatus quintiles (SES-HCI) on the vertical axis, against log real GDP per capita on the horizontal axis, for the 51 countries in the SES-HCI dataset. For each country, the solid dot denotes the average across quintiles, and the top (respectively, bottom) of the vertical bar denotes the value for the top (respectively, bottom) quintile. Light-grey points show the HCI for countries where the SES-HCI is not available. 
Figure 2. Proportion of 10-19-Year-Old Children Who Attain Each Grade, by Wealth Quintile
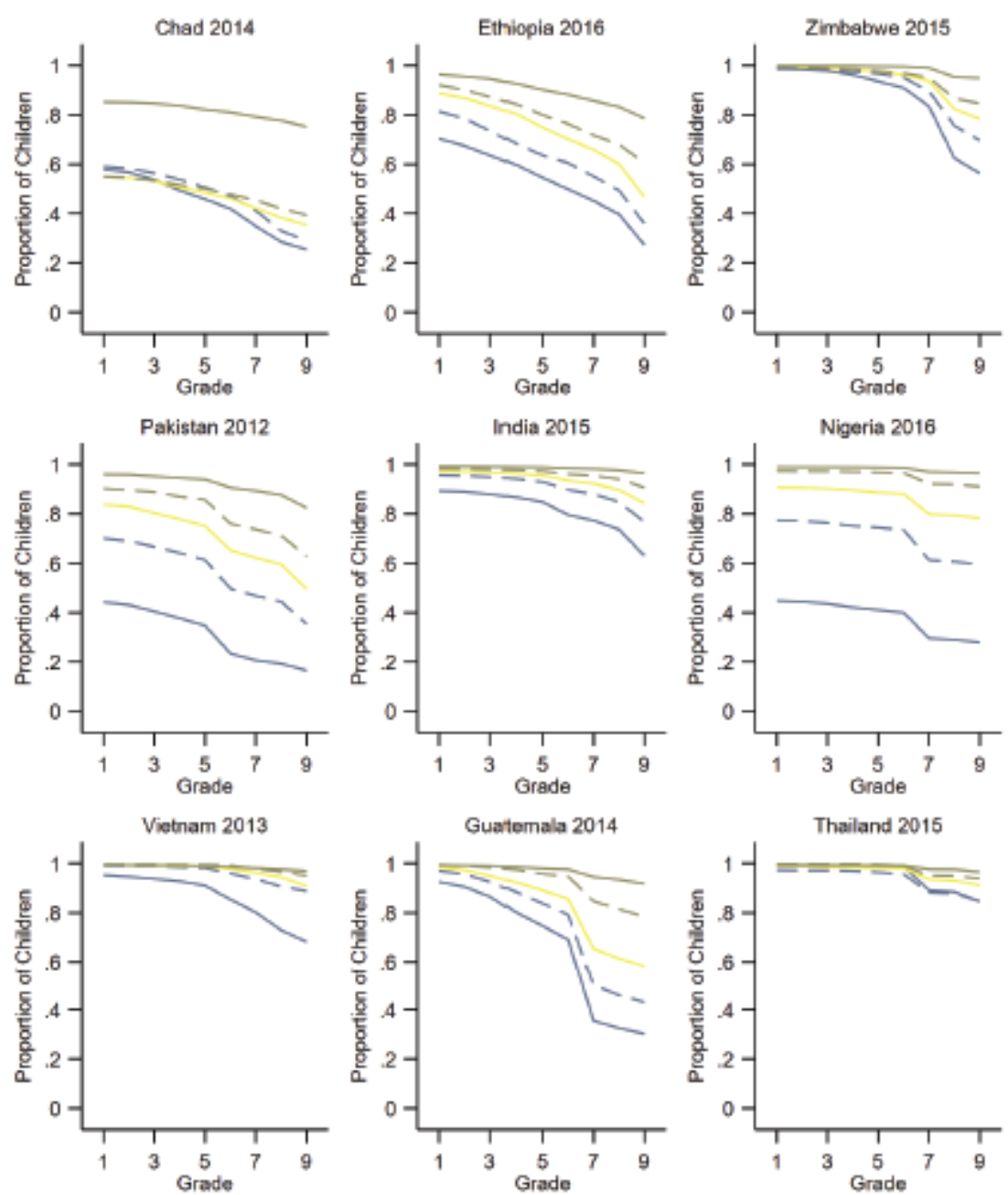

- Poorest quintile

- - Quintile 2

Quintile 3

- - Quintile 4

- Richest quintile

Source: Avitabile et al. (2020), figure 2.4. License: CC BY 3.0 IGO. 
Figure 3. Socioeconomic Gradient in Child-Survival Rates by Country Income Level

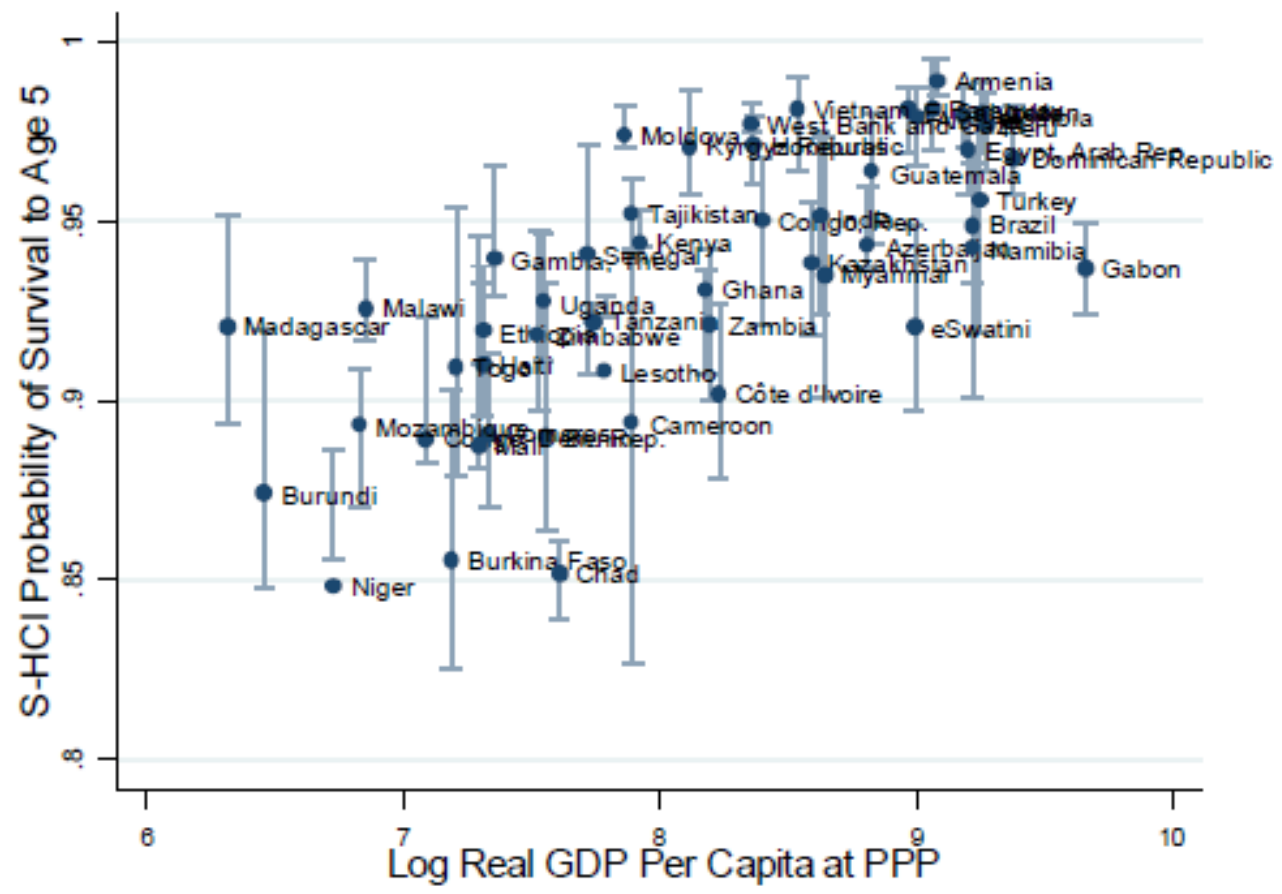

Source: D'Souza et al. (2019), figure 1. License: CC BY 3.0 IGO.

Note: The figure depicts child-survival rates (probability of survival until age 5) disaggregated by socioeconomic quintile on the vertical axis, against log real GDP per capita on the horizontal axis, for the 51 countries in the SES-HCI dataset. Solid dot denotes average across quintiles, and top (bottom) of vertical bar denotes value for the top (bottom) quintile. Country average (dot) may fall below value for lowest quintile (bottom end of vertical bar) when middle quintiles have values below lower quintiles (for instance, Niger). 
Figure 4. Socioeconomic Gradient in Non-Stunting Rates by Country Income Level

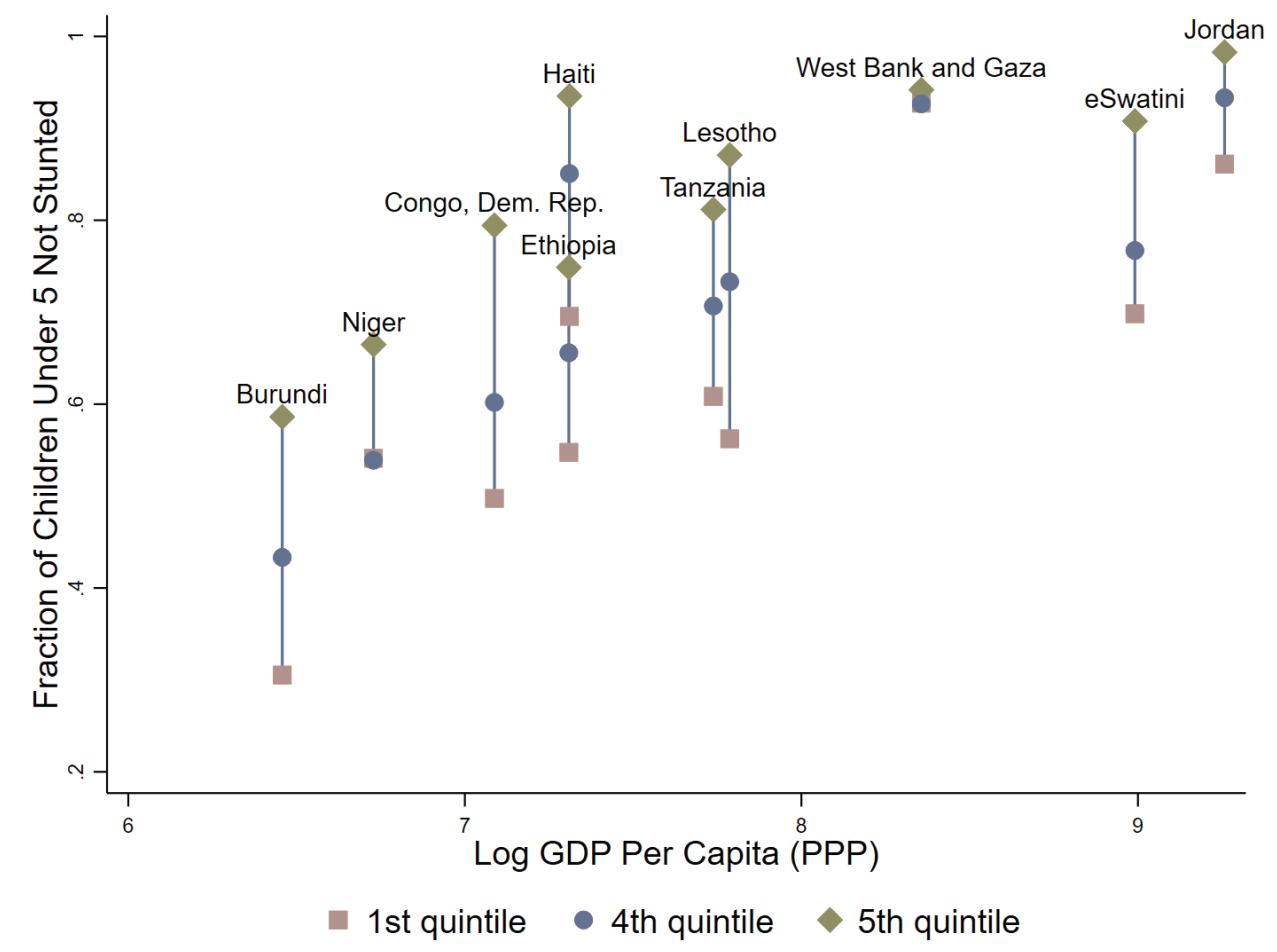

Source: Avitabile et al. (2020), figure 2.3. License: CC BY 3.0 IGO.

Note: Stunting, an indicator of chronic malnutrition, means that a child has low height-for-age. It is defined as a height-for-age more than 2 standard deviations below the median of a healthy reference population. 
Education and health policies should reflect certain common principles. The broad policy goals should be to improve:

- The quality, and not just the quantity, of education and health care.

- Outcomes for disadvantaged groups, who are worse served by current systems. The return to investing in these groups is especially high, particularly in countries with the largest equity gaps, and especially for measures early in life.

- $\quad$ Lifelong outcomes, especially because (working) lives are steadily lengthening.

The means to achieve these goals, while maximizing value for money, include:

- $\quad$ Focusing on results-learning and good health — rather than just inputs, such as education and health spending.

- Moving from narrow, piecemeal interventions to systemic reform, centered on efforts to increase accountability and improve incentives, including by empowering citizens.

- $\quad$ Adopting a "whole-of-society" approach. Government departments largely function along discrete lines, often with minimal inter-sectoral cooperation. Coordinating efforts within government to reflect important interactions between policies, and sustaining such efforts across political cycles, can foster policy coherence and effectiveness. Partnership with the private sector and civil society can, in turn, complement government action in helping improve the coverage and quality of service delivery. In particular,

Supply-side measures to strengthen education and health systems must be complemented by demand-side measures to help families accumulate human capital by easing financial constraints-for instance, through conditional cash transfers, or reconnecting workers with jobs.

Different dimensions of human capital reinforce each other- "skills beget skills". There are therefore important complementarities among different policy measures (Cunha and Heckman 2007). For instance, improvements in sanitation and nutrition that enhance children's health complement teacher training in boosting learning.

Reforms must be underpinned by a robust evidence base. Evidence helps stakeholders judge system performance, reveals opportunity gaps, and catalyzes action. It shines a light on constraints, enabling policymakers to design effective interventions and target support to the most vulnerable. It shows whether reforms are working and suggests ways to refine them. Its importance is multiplied during crises: governments that use relevant real-time data can better respond to both immediate and long-term challenges. 
These themes do play out differently with regard to education and to health care. We explore these two policy areas in turn, summarizing key messages from the academic and policy literature.

\section{EduCATION ${ }^{6}$}

\section{A. The learning crisis and its causes}

In many education systems, children learn very little-a true learning crisis. Even after several years, they remain unable to read a simple story or do basic addition and subtraction. Fiftythree percent of all 10-year-old children in low- and middle-income countries, and 93 percent of those in LICs, cannot read and understand a simple age-appropriate story ("learning poverty"; World Bank 2019). In rural India, only half of grade-5 students fluently read grade- 2 text, such as "It was the month of rains". In Ghana and Malawi, more than three-fifths of students ending grade2 cannot read a single familiar word such as "the" or "cat". In Nicaragua, only half of grade-3 students can solve "5 + 6" (World Bank 2018).

While not all developing countries suffer from such extreme shortfalls, many fall far short of the levels they aspire to. International assessments of literacy (PIRLS) and numeracy (TIMSS) show the average student in LICs performs worse than 95 percent of students in high-income countries. Many high-performing students in middle-income countries, who rank in the top quarter of their cohorts, would rank in the bottom quarter in a wealthier country. In Algeria, the Dominican Republic, and Kosovo, test scores of students at the cutoff for the top quarter of students are well below the bottom-quarter cutoff in OECD countries, as measured by the PISA assessment (Figure 5). Even in Costa Rica, a relatively strong performer, performance at the cutoff for the top quarter of students equals performance at the bottom-quarter cutoff in Germany. While some countries are making progress, this is typically slow.

The learning crisis amplifies inequality: it hobbles especially severely the disadvantaged youths who most need a good education. The most disadvantaged suffer from the worst access to schooling, highest dropout rates, and largest learning deficits. Differences by income level are stark (Figure 6). At the end of primary school, only 5 percent of girls in Cameroon from the poorest quintile had learned enough to continue schooling, compared with 76 percent of girls from the richest quintile. Learning outcomes are also highly unequal along disability, gender, and ethnic lines; displaced children typically fare worse even when in school. These learning gaps often grow with more years in school. And learning inequalities are particularly high in more unequal societies, partly reflecting a greater learning gap between public and private schools and greater socio-economic sorting across school types (Patel and Sandefur 2020). On the TIMSS assessment,

\footnotetext{
${ }^{6}$ This section draws heavily on World Bank $(2018,2020 \mathrm{~b}, 2020 \mathrm{f})$. It focuses on foundational skills, such as literacy, numeracy, and basic reasoning, acquired from birth through secondary school. These skills provide the critical foundation for higher-order reasoning, creativity, and socioemotional skills like perseverance and teamwork. They allow adaptability and lifelong learning.
} 
the gap between the top and bottom quarter of U.S. students is larger than the median-score gap between the United States and Algeria.

Figure 5. In several countries, the $75^{\text {th }}$ percentile of test-takers performs below the $25^{\text {th }}$ percentile of the OECD average (2015 PISA mathematics assessment)

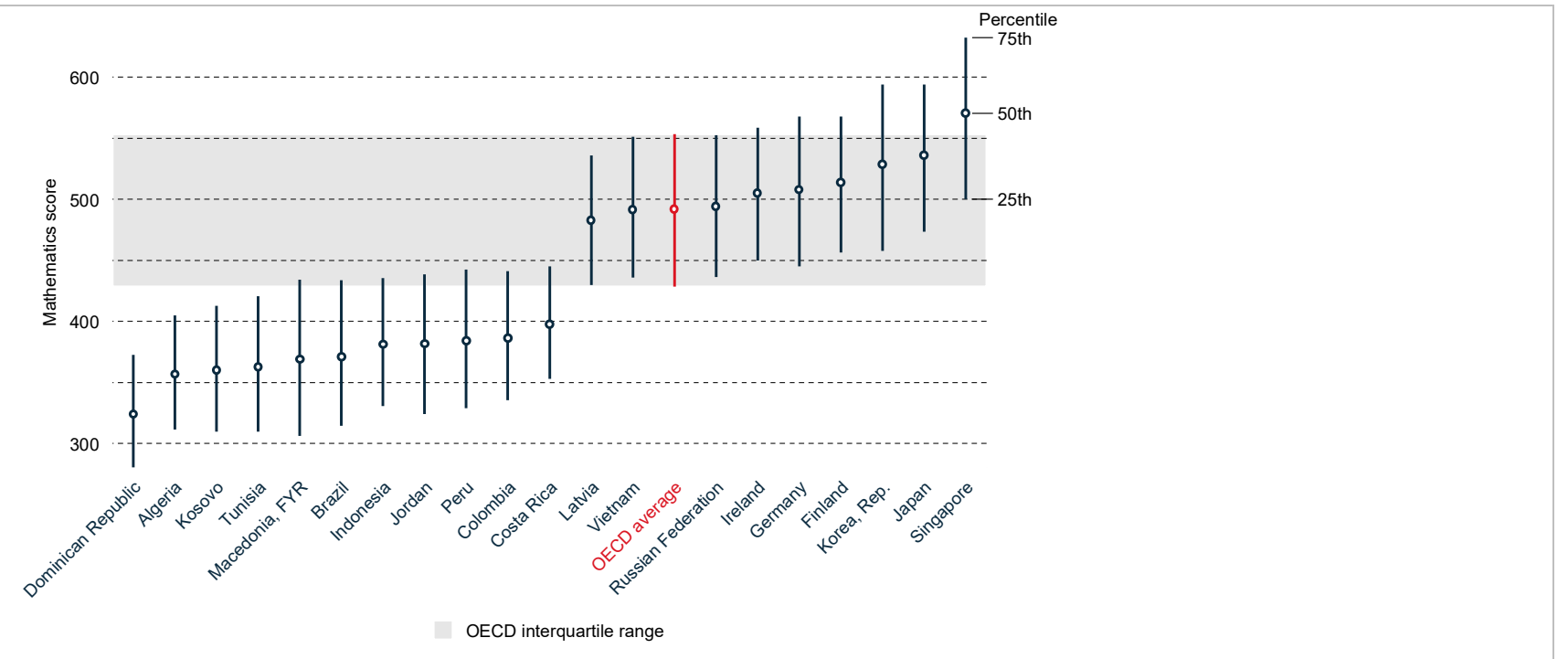

Source: World Bank (2018), figure O.2. License: CC BY 3.0 IGO.

Figure 6. Children from poor households in Africa typically learn much less

Percentage of grade-6 PASEC test-takers who score above (blue) and below (red) the sufficiency level on reading achievement: poorest and richest quintiles by gender

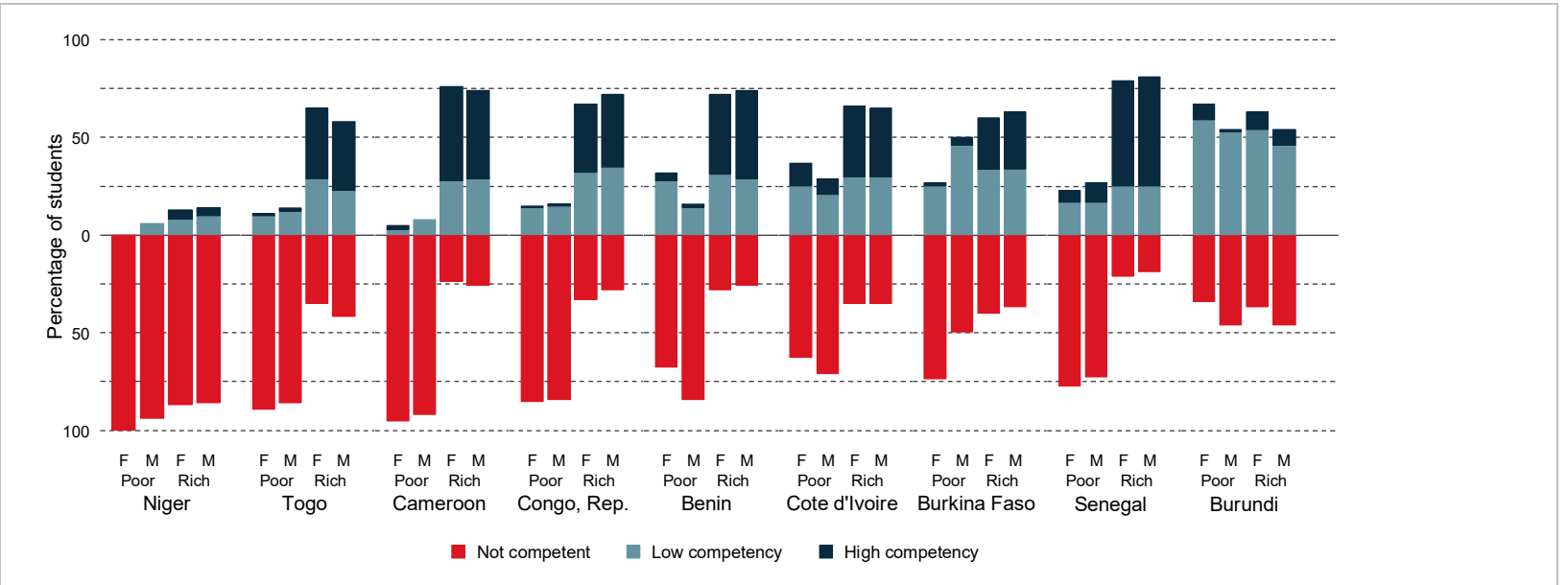

Source: World Bank (2018), figure O.3. License: CC BY 3.0 IGO.

Note: Quintiles are nationally defined. Not competent refers to levels $0-2$ in the original coding, and is below the sufficiency level for school continuation; low competency refers to level 3; high competency refers to level 4.

Millions of disadvantaged children remain out of school, because of conflicts, poverty, and the learning crisis itself. Enrollment gaps in basic education between high- and low-income 
countries are closing. But even before COVID-19 one-fifth of children of primary- and secondaryschool age, and 10 percent of primary-school age children in low- and lower-middle-income countries, remained out of school (UNESCO 2020). Worldwide, only half of all three- to six-yearolds have access to pre-school education; in LICs, just one-fifth do. Conflict-affected countries account for a disproportionate one-third of out-of-school children. But almost all developing countries have pockets of out-of-school children from excluded groups. Poverty most consistently predicts failing to complete schooling; gender, disability, caste, and ethnicity contribute. And, when poor parents perceive education to be of low quality, they become less willing to sacrifice to keep children in school.

The COVID-19 pandemic both exposed and magnified existing inequalities. Disadvantaged groups, including poor and rural children, were disproportionately affected by school closures (OECD 2020, Lustig et al. 2020, Garcia Jaramillo 2020). They had less capacity to learn at home: they suffered from the digital divide, including differences in access to hardware, connectivity, the right software, teachers with digital skills, and schools with the resources to provide remote learning ${ }^{7}$ less educated parents could provide less support; and poorer parents could not afford private tutors. And the disadvantaged, including in particular adolescent girls and the disabled, were at greater risk of dropping out (UN 2020b). The impact on learning will likely prove large (World Bank 2020e) and persistent (Andrabi et al. 2020).

\section{Immediate causes of the learning crisis}

\section{Struggling education systems typically lack some key school-level learning ingredients:}

- Children arrive in school unprepared to learn. Malnutrition, illness, low parental investments, and the harsh environments associated with poverty undermine early childhood learning and weaken developmental foundations. ${ }^{8}$ These deprivations have long-lasting effects because they impair infants' brain development, and the brain becomes less malleable with age.

- $\quad$ Teachers lack the skill, motivation, or support to be effective. Teachers are the most important factor affecting learning in schools (Schleicher 2018). U.S. students with great teachers advance three times faster than those with a poor teacher; in developing countries, teacher quality can matter even more (Bau and Das 2017). And teacher salaries are the largest single education-budget item, taking up three-quarters of the primary-level budget in developing countries. Yet many systems struggle to attract strong candidates into

\footnotetext{
${ }^{7}$ Around one-third of schoolchildren worldwide lack all access to remote learning via radio, television, or online content (UNICEF 2020).

${ }^{8}$ McCoy et al. (2016), Schady et al. (2015). Thirty percent of under-5 children in developing countries are physically stunted, typically reflecting chronic malnutrition.
} 
teaching (Bruns and Luque 2014), and to provide a solid foundation of subject or pedagogical knowledge before they start teaching. ${ }^{9}$ Continuing professional development is inconsistent, overly theoretical, and often expensive. There are few mechanisms in place to mentor, support, and motivate teachers. Substantial learning time is lost because classroom time is spent on other activities or teachers are absent (Bold et al. 2017). The problems are particularly severe in rural or remote communities.

- Inputs fail to affect learning. Often, inputs do not even reach the frontlines. In Sierra Leone, textbooks were distributed to schools, but most were locked up unused in cupboards (Sabarwal et al. 2014). In Brazil, the One Laptop per Child initiative faced years of delays. One year after the laptops finally made it to classrooms, more than 40 percent of teachers had never or rarely used them (Lavinas and Veiga 2013).

- Management and governance are weak. Effective school leadership improves teaching quality, ensures effective resource use, and boosts student performance, even after controlling for student and school characteristics (Adelman and Lemos 2020, Robinson et al. 2008). School principals can actively help teachers solve problems, provide instructional advice, and set goals that prioritize learning. But management capacity is substantially lower in schools than in manufacturing, and particularly weak in LICs (Bloom et al. 2015). And schools often lack decision-making autonomy, while community engagement fails to provide oversight (Bruns et al. 2011).

These quality problems are concentrated among disadvantaged children, amplifying social inequalities. In LICs, among children under 5, stunting rates, an indicator of chronic malnutrition, are almost three times higher in the poorest quintile than the richest. Problems with teacher absenteeism, lack of inputs, and weak management are most severe in poorer communities.

\section{Systemic causes of the learning crisis}

Low learning levels ultimately reflect both technical and political challenges, which help explain poor learning conditions in schools and communities.

\section{Technical challenges}

Many countries, and particularly LICs, collect little systematic information on learning; this makes it difficult to monitor and manage learning activities. Teaching involves significant discretion and regular, repeated interactions, making it challenging to manage learning (Andrews et al. 2017). Many systems lack the reliable, timely assessments of student learning and of teaching quality needed to provide feedback on performance. More than one-fifth of children in low- and middle-income countries, and 54 percent of children in Sub-Saharan Africa, live in countries with

\footnotetext{
${ }^{9}$ In Sub-Saharan Africa, less than 20 percent of grade-4 teachers have mastered the curriculum they teach.
} 
no or dated learning assessment data (World Bank 2019). One-third of countries lack information on reading and mathematics proficiency of children at the end of primary school. Even more lack it for the end of lower secondary. Available data are often from one-time assessments that do not allow tracking over time.

All parts of the education system must be coherent. A new curriculum that emphasizes active learning and creative thinking will not change much per se. Teachers must be trained and motivated to use active learning methods, which are more demanding than rote learning. Unreformed exams can weaken the effect of curriculum reform through misaligned incentives: in Korea, the curriculum now focuses on students' creativity and socioemotional skills, but many parents still send their children to private "cram schools" to prepare for high-stakes universityentrance exams (Park 2016).

The need for coherence makes it risky to borrow system elements from better-performing countries. Finland's high-performing system gives considerable autonomy to its well-educated teachers, who tailor teaching to student needs. But in lower-performing systems, where teachers are poorly educated, unmotivated, and loosely managed, giving them more autonomy may worsen outcomes (Chisholm and Leyendecker 2008).

\section{Political challenges}

Many education actors have interests beyond learning. Politicians may focus benefits on their base, for example awarding education jobs through patronage rather than based on merit. Bureaucrats may protect their position by keeping politicians and teachers happy. Private education suppliers may act against students' interests to boost profits. Teachers may fight to protect employment and incomes. Higher-income urban families press for investments to benefit their children, diverting funding from poorer communities. Families in private schools are less willing to pay for public schools. Various actors use education to promote particular ideologies. Especially in poorly managed systems, policy choices are determined by who the more powerful actors are — not by what improves learning.

Potential beneficiaries of learning - students, parents, and employers-face difficulties in organizing themselves or acquiring the information needed for reforms. Parents are usually not organized to participate in system-level debates, may lack knowledge of potential reform gains, and may fear opposing teachers, bureaucrats, and politicians. Students may ignore how little they are learning. Employers facing skilled-worker shortages may lobby for lower taxes rather than quality education. Conversely, potential losers from reform are aware of what is at stake and are better organized to act collectively. Particularly in low-trust, risky environments, it is often in each individual's interest to maintain the status quo. 


\section{B. Three policy responses}

Education systems must make learning a serious goal, through three complementary strategies. These will both improve short-term service delivery for current students, and establish systemic changes to boost long-term outcomes (World Bank 2020f).

- $\quad$ Assess learning: measure student learning to spotlight inequalities and spur action.

- $\quad$ Make schools work for learners: use evidence to guide innovation and practice.

- $\quad$ Reform the system: tackle technical and political barriers to learning.

The relationship between public spending per se and educational outcomes is often weak. Public spending does not correlate strongly with learning, or even access to education, even among countries at similar development levels (World Bank 2018, spotlight 6; Al-Samarrai et al. 2019). Across systems and schools, similar levels of resources are associated with vast differences in outcomes. Likewise, increases in spending have limited effects on learning. ${ }^{10}$ Spending has particularly weak effects in countries with weak governance (Suryadarma 2012; Rajkumar and Swaroop 2008). Adopting a more granular approach, specific interventions focused on providing inputs alone, such as more teachers or greater salaries, generally boost neither access nor learning (Angrist et al. 2020, Global Education Evidence Advisory Panel 2020). Direct school grants have often increased student enrollment and retention, but with limited effects on learning.

However, increased financing can support improvements in learning, if it is complemented by and supports broad reforms - that is, "spending more and better" (Gaspar et al. 2019). Currently, funds sometimes fail to reach schools, or pay for inputs that do not improve teacherlearner relationships. And financing is allocated inequitably, reducing overall learning (IMF 2017): poor and rural communities receive fewer education resources, including materials and staff (Jackson 2020, Lafortune et al. 2018), and relatively large amounts are devoted to secondary and tertiary education, which marginalized children are less likely to complete than primary education. More financing for business-as-usual will not change outcomes. But where countries seriously tackle barriers to learning for all, education spending is a critical investment. Good teachers, conducive learning environments, reliable assessment systems, and innovative learning technologies all cost money. Even with greater efficiencies, more children staying in school longer will require more financing, especially in countries that currently invest little in education.

\section{A short-term step towards the goal of improved learning is to ensure a sustained commitment} to financing education in the wake of the COVID-19 crisis, with funding prioritized based

\footnotetext{
${ }^{10}$ Kenya and Lesotho both increased public spending per primary-school student during the 2000s; learning improved in Lesotho but decreased in Kenya. Guatemala reduced per-student spending during 2006-13, as did Bulgaria during 2009-15; in both cases, learning improved significantly.
} 
on both need and effectiveness (World Bank 2020b). Sharp cuts in public education spending, at a time when households are less able to support children's education, would further widen outcome gaps and cause long-term damage. To prevent this, it is important to support those with the greatest need, for instance through formula-based funding that prioritizes support to disadvantaged households and areas. At the same time, tight post-crisis budgets make it even more important to engage in proven, high-return interventions.

We now discuss the three complementary strategies that will greatly increase the likelihood that education spending leads to learning for all.

\section{Assess learning}

Better data on learning gaps will help catalyze reforms. Germany's "PISA 2000 shock"when new international learning comparisons showed mediocre scores and large achievement gaps in that country - led to successful reforms. In Bangladesh, India, and Tanzania, widely publicized results from citizen-led learning assessments shifted the government's focus toward learning.

Many different learning metrics are required. Assessment by teachers in classrooms helps tailor teaching to students' needs. Singapore identifies lagging grade-1 students through screening tests, then gives them intensive support. National and subnational learning assessments provide system-level insights on students' learning, lagging groups, drivers of achievement, and progress over time. International assessments raise awareness of how a country falls short of its peers, and can be powerful tools politically. Other learning metrics can strengthen the quality and equity of assessments. Grassroots accountability movements - led by civil-society organizations like ASER in India and UWEZO in East Africa-have deployed citizen-led assessments to measure the foundational learning of young children in their communities, using the data to advocate for reform. Some household surveys collect learning data, enabling assessment of out-of-school children, and analysis of how learning correlates with income and community variables. All these learning metrics can function as a check on each other's accuracy.

Metrics must be designed and used judiciously, or they could prove misleading. They may not capture important educational dimensions; the MDG of universal primary education did not capture foundational literacy and numeracy skills, let alone other life skills (the SDGs have filled this gap). If assessments are poorly designed or implemented, they may encourage shallow forms of learning such as rote memorization, or provide administrators or educators incentives to cheat.

The barriers to better measurement of learning are both technical and political. Teachers may lack the training to assess learning effectively, and especially to capture higher-order skillsthrough project-based assessment, say. Education ministries may lack capacity to design and implement valid assessments. Policymakers may prefer to avoid testing and be assumed ineffective, rather than to test and remove all doubt; or they may decline to publish test results (like Mexico with the 1995 TIMSS assessment). 


\section{Make schools work for learners}

There are three entry points for policy to improve school-level outcomes: prepared learners, effective teaching, and inputs and management that affect learning. Hundreds of systematic evaluations from multiple contexts demonstrate that many educational interventions substantially improve learning and boost earnings, and identify the channels (Angrist et al. 2020, Evans and Yuan 2017). Some of the most cost-effective programs deliver the equivalent of three additional years of high-quality schooling for just $\$ 100$ per child. Specific solutions do need to be tailored to local contexts. The key is to use evidence to guide local innovation, and monitor learning to evaluate what works in a given setting.

Preparing children for learning is the critical first step. Priorities include:

- Early childhood development services, including nutrition, stimulation, and care. In Jamaica, a program to improve cognitive and socioemotional development led to lower crime rates, better mental health, and earnings that were 25 percent higher 20 years later (Gertler et al. 2014). Working through parents and across ministries is essential here.

- Lower school costs to get children into school, but then use other tools to boost motivation and effort. Fee reductions and conditional cash transfers are highly effective in getting children to school, even in fragile contexts, but design matters as to whether they affect learning (Barrera-Osorio and Filmer 2016). Groups with high dropout risk, such as girls or students from marginalized communities, and their parents and teachers, should receive targeted support and communications, including socioemotional support (World Bank 2020b).

- $\quad$ Since many youths leave basic education lacking skills, provide remedial education before further education and training. Universities in both Mexico and Chile have developed structured programs to assist students in their transition to higher education.

To boost teacher skills and motivation, the teaching profession must be reshaped as a meritocratic, socially valued career. Teachers must be held to high professional standards, and be given the corresponding tools and support. Key principles include:

- $\quad$ Teacher training should provide sufficient subject-content knowledge and mastery of core pedagogical practices. It must recognize that the role of teachers is increasingly to facilitate learning, including teaching students how to learn, and not simply to deliver content. Preservice training should allow extensive practice; in-service professional development must be individually tailored, practical, repeated, with follow-up coaching - often around a specific pedagogical technique (Kraft et al. 2018; Darling-Hammond et al. 2017; Popova et al. 2016, 2019). Teachers should be supported with proven, structured lesson plans (Béteille and Evans 2019). Training systems should incorporate an integrated, diversified set of measures to evaluate teachers' practices and effectiveness, including evidence of learning, direct observation, videotapes, artifacts, and student surveys (Bill and Melinda 
Gates Foundation 2010). Value-added measures of student achievement tied to individual teachers must take into account potential differences in student and school characteristics, and as a result should not generally be used for high-stakes decisions (Darling-Hammond et al. 2012).

- $\quad$ Target teaching to the level of the student, to keep learners from falling behind to the point where they cannot catch up (J-PAL 2018). Effective tactics include improved classroom assessment, to identify learning gaps; having community teachers provide remedial lessons (Banerjee et al. 2007, 2010); reorganizing classes by ability (Banerjee et al. 2016, Duflo et al. 2011); teaching students in their first language - globally, 40 percent of children are still taught in a language they do not fully speak or understand (Lyytinen et al. 2019); and using technology to adapt lessons to individual needs, including computer software (Muralidharan et al. 2019) or text messages (Angrist et al. 2020b). These efforts need clear system-level guidance and materials; focused, practical training for principals and teachers; and substantial resources.

- Use pecuniary and nonpecuniary incentives to improve teacher motivation, ensuring that the incentivized actions are within teachers' capacity. Linking teacher pay or career progression to learning outcomes is often effective (Brazil, India, Israel, Kenya, and Peru). However, design details matter (Bruns et al. 2011). And it is important to secure buy-in from teachers, as shown by Chile's successful, long-running, national-level "pay-forperformance" scheme.

Effective teaching also requires engaging parents. Parents play a critical role in supporting children's learning, and need to be involved from the earliest years (Shonkoff and Fisher 2013). Parents should therefore be provided with appropriate guidance and resources, including through coaching on positive discipline and how to engage in stimulating activities with their children, and effective parent-teacher connections (Vegas and Winthrop 2020).

School inputs, management, and governance must focus on improving learning. To this end,

- New technology, including for remote learning, must be implementable in current systems and reach all learners (World Bank 2020b, 2020d). Education technology (including hardware, software, digital content, data, and information systems) can enhance system performance, equity, and resilience. It can help assess learning, improve teacher skills, customize instruction, manage service delivery, and ensure that resources reach all (J-PAL 2019). It can foster new connections between teachers, students, parents, and broader communities to create learning networks. It can strengthen lifelong learning and reach out-of-school children. And it can assist in implementing change at scale, quickly, and cost-effectively. But many technology interventions fail because they are ill-adapted to their setting - complementary infrastructure or the knowledge on how to use technology is missing. And effectiveness hinges on incorporating feedback from parents, teachers, and school-leaders, as seen in Peru (Vegas and Winthrop 2020). In particular, remote 
learning should be designed for scale for all children, using technology already widely available in-country. In LICs, this may involve low-tech solutions, such as radio or TV. More generally, it will require multi-modal delivery - for instance, radio, text-messaging, print materials, and online learning. And scaling up effectively requires a whole-ofgovernment, multi-stakeholder approach, bringing together the entire education ecosystem including telecom companies, publishers, local EdTech startups, and radio and TV stations.

- Inputs, including technology, must complement rather than substitute for teachers (Snilstveit et al. 2016). Credible plans for integrating technology into teaching are critical. Technology should enhance teachers' access to content, data, and expertise, allowing for real-time adaptation. When a computer-assisted learning program in India complemented regular lessons, it increased learning, especially for initially poorer-performing students. When it substituted for lessons, it decreased learning. As a corollary, countries should invest in teacher (and student) digital skills.

- School-management and governance reforms should foster innovation in learning; decision-making autonomy must be framed by clear mandates and accountability

structures. School-leaders should be pedagogical leaders, closely involved in student learning, mentoring teachers, and engaging with the wider community, rather than simply performing administrative duties. Student learning is significantly increased by programs that train principals in providing feedback to teachers on lesson plans, regular learner assessments, action plans to improve student performance, and teachers' classroom performance (Fryer 2017). Mentoring and coaching of principals from experienced school leaders is also effective (Nannyonjo 2017), as is clarifying the respective management roles of district officers, school principals, and teachers (Lassibille 2016). Involving parents and communities in school governance, supported by solid learning metrics, can complement such efforts (Beasley and Huillery 2017).

\section{Reform the system}

Deploying effective school-level programs is insufficient. Replicating experimental interventions across the entire school system often fails because of systemwide constraints. Cambodia scaled up early childhood development centers and preschools-programs that had worked in some parts of the country when implemented by NGOs. But there were no improvements in child development, as parents' demand for the services remained low, reflecting: limited ability to absorb the associated costs (for instance, new clothing or school supplies); lack of information on the benefits; and the low quality of the programs provided, in terms of location, hours of operation, and/or intensity (Bouguen et al. 2013). Kenya tried to lower student-teacher ratios by hiring contract teachers - an intervention that improved student outcomes when implemented by NGOs. But the results were negligible, reflecting implementation and politicaleconomy constraints (Bold et al. 2013). When Indonesia tried to increase teacher effectiveness by nearly doubling the salaries of certified teachers, political pressures watered down the certification 
process but left the pay increase in place. The result: much larger expenditure, but no increase in teacher skills or student learning (De Ree et al. 2017).

School-level interventions boost learning and equity systemwide only if countries tackle the system-level technical and political barriers to change discussed earlier. Reformers can use two sets of tools: form coalitions to advocate for learning and to rebalance political incentives; and innovate flexibly, using evidence to identify where to start, and metrics to adapt.

\section{Coalitions and incentives}

Mobilize everyone with a stake in learning. Many countries have used wide-ranging consultations to build support for reforms. Malaysia used a "lab" model to bring together coalitions of stakeholders and involve them in all stages of reform, from design to implementation Communication campaigns can mobilize citizens. In Peru, information on poor learning mobilized support for strengthening teacher accountability. It catalyzed action by businesses, which funded campaigns highlighting the importance of quality education for economic growth. And parents protested teacher strikes that disrupted schooling (Bruns and Luque 2014). Another coalitionbuilding tool is bundling reforms, so that everyone achieves a top priority. Modernizing vocational training can buy employers' support for broader reforms.

A negotiated, gradual approach to reform is more promising than confrontation. Fostering collaboration around shared goals boosts the chances of success. In Chile, successive negotiations between the government and the teachers' union built broad support for reforms that linked pay and career development more closely to performance, while also improving teachers' working conditions, raising overall salaries, and boosting resources for education (Mizala and Schneider 2012). Regular discussions on the implementation of reforms further increased trust. Several countries have compensated actors who might lose from reforms, or phased in changes to protect incumbents; in Peru and Washington, D.C., pay-for-performance schemes were initially voluntary.

Form strong partnerships between schools and their communities. Local-level community engagement can complement national change efforts, or substitute for them where political and bureaucratic reform incentives are weak (Mansuri and Rao 2012). In South Africa, political and economic constraints hampered efforts to improve national education performance. Yet progress was made in improving outcomes at some local levels through strong parent-school partnerships.

\section{Innovation and agility}

Innovation and adaptation are critical to developing learning approaches that fit different contexts and changing circumstances. The better-performing parts of any system can suggest feasible approaches. Argentina's Misiones Province had high dropout rates, but some schools bucked the trend, reflecting more constructive teacher-parent relationships. When other schools adopted this approach, dropouts fell significantly (Green 2016). As Burundi recovered from civil war, an adaptive approach to getting textbooks to schools reduced delivery times in some areas from over a year to sixty days - and was then replicated in other areas (Campos et al. 2015). 
Incentives determine whether systems innovate and adopt emerging solutions at scale. Closed systems that limit teacher and school autonomy, and judge performance by compliance with resource-use rules, provide little room for innovation. Open systems that focus on results rather than inputs, and provide flexibility in using financing, will see greater innovation and diffusion of new approaches (Andrews et al. 2013). But innovations must be supported by good metrics and system-level coalitions-otherwise, improvements will prove short-lived or geographically limited.

\section{Health Care}

\section{A. The challenges}

Living long, healthy lives is a common aspiration across all societies; but significant challenges stand in the way of achieving this goal, particularly for the disadvantaged. The past few decades represented a golden era for global health. During 1950-2019, global life expectancy increased from 46 years to 73 years; mortality from infectious diseases fell especially sharply. Developing countries in particular saw vast increases in access to health services (including antenatal care, vaccinations, and HIV treatments) and other health determinants (such as clean water and sanitation). But the world faces both an unfinished health agenda, and emerging challenges. In LICs and lower middle-income countries (LMICs), poor and rural households still experience high rates of infectious disease; reproductive, maternal, newborn, and child health disorders; and malnutrition. Meanwhile, most countries face a rapidly growing burden from noncommunicable diseases (NCDs; for instance, cardio-vascular disease, cancer, chronic respiratory conditions, diabetes, and mental health), ${ }^{11}$ reflecting rising exposure to behavioral and environmental risk factors ${ }^{12}$ and the impact of population aging. NCDs are diseases of slow progression and long duration. Their initial onset is occurring at increasingly younger ages, implying that people will spend more years living with chronic conditions and disability and will face greater health-care needs. At older ages, NCDs are associated with comorbidities that interact with them and complicate treatment and care. Looking ahead, the world is underprepared for emerging health threats, including new pandemics, as illustrated by the COVID-19 crisis (Bill and Melinda Gates Foundation 2020, Winskill et al. 2020, UNDP 2020); antimicrobial resistance (Prestinaci et al. 2015); and global climate change (Lancet Commission on Health and Climate Change 2015). In general, poor populations are most exposed to these challenges, reflecting greater vulnerability to risks and less ability to access or afford preventive services and treatment.

\footnotetext{
${ }^{11}$ NCDs now account for 71 percent of all deaths globally, and more than half of all lost disability-adjusted life-years (Global Burden of Disease Study 2017). Their prevalence has increased rapidly across all advanced and developing regions.

12 Including unhealthy diets, physical inactivity, smoking, alcohol misuse, and air pollution, also through their impact on obesity, cholesterol, and hypertension.
} 
Late diagnosis, owing to delays in seeking care, often leads to more chronic illness and complications.

Building health systems that achieve better outcomes for all, and are resilient to crises, requires making significant progress towards universal health coverage (UHC) (UHC2030 2020). There are three key dimensions to UHC (WHO and World Bank 2013):

- Coverage for the entire population, regardless of socioeconomic status, geographic location, gender, age, or preexisting conditions - including coverage for groups, such as poor, rural, and informal-sector workers, that in many developing countries are largely uncovered.

- $\quad$ Financial protection from direct payment for health services - in particular, protection from catastrophic or impoverishing health expenditures. ${ }^{13}$

- $\quad$ Access to a full spectrum of essential, quality health services according to need.

A pro-poor pathway to UHC, which prioritizes expanding coverage and financial protection for all groups including the disadvantaged (a "progressive universalism"), will deliver large benefits (Lancet Commission on Investing in Health 2013, WHO 2014). Indeed, coverage expansion should target the most vulnerable first: better-off households have more options for obtaining coverage and are more resilient in the face of unexpected medical bills. The emphasis should be on health interventions that provide good value for money, address a significant disease burden, are feasible to implement in a range of countries, prioritize the worse-off, and increase protection against financial risks. Examples include a wide range of maternal and child health services, interventions against HIV/AIDS and tuberculosis in adults, and various interventions to address NCDs and injuries (Watkins et al. 2017).

Many developing economies are far from achieving UHC, which generates deep inequalities. Less than half the world's population is covered by essential health services (WHO 2019). Each year, approximately 90 million people fall into poverty, and 900 million people encounter serious hardship, from paying for health services; lower-income households are far more likely to have to spend a large income share on out-of-pocket payments; and many others forgo care because of prohibitive costs (WHO and World Bank 2019). Conversely, achieving UHC will help households both prevent and better manage health shocks and their financial consequences.

Improving health outcomes, and meeting growing health-care demands, must be achieved without unduly burdening household or government budgets. This is possible, given that

${ }^{13}$ Health expenditures are described as "catastrophic" if they exceed some significant share (say, 10 percent) of total household expenditure, and "impoverishing" if they push households below the poverty line. 
similar levels of health expenditure translate into vastly different outcomes in different health systems - just as was true of education (Figure 7; Barber et al. 2020). Relatedly, greater health expenditure does not automatically translate into improved outcomes. Still, in some countries, public health expenditure must clearly increase (Gaspar et al. 2019). It currently averages less than $\$ 10$ per capita in LICs, and $\$ 30$ in LMICs, reflecting both their low capacity to mobilize revenues and the relatively small share of government spending allocated to health (World Bank 2019c). The annual cost of a package of essential, high value-for-money services that could facilitate the achievement of the health-related SDG targets equals on average \$79 per capita in LICs, and $\$ 130$ per capita in LMICs. ${ }^{14}$ Providing this package would on average require additional investments of 8 percent of national income in LICs, and 4.2 percent of national income in LMICs.

Figure 7. Relationship between childhood stunting and health expenditure.

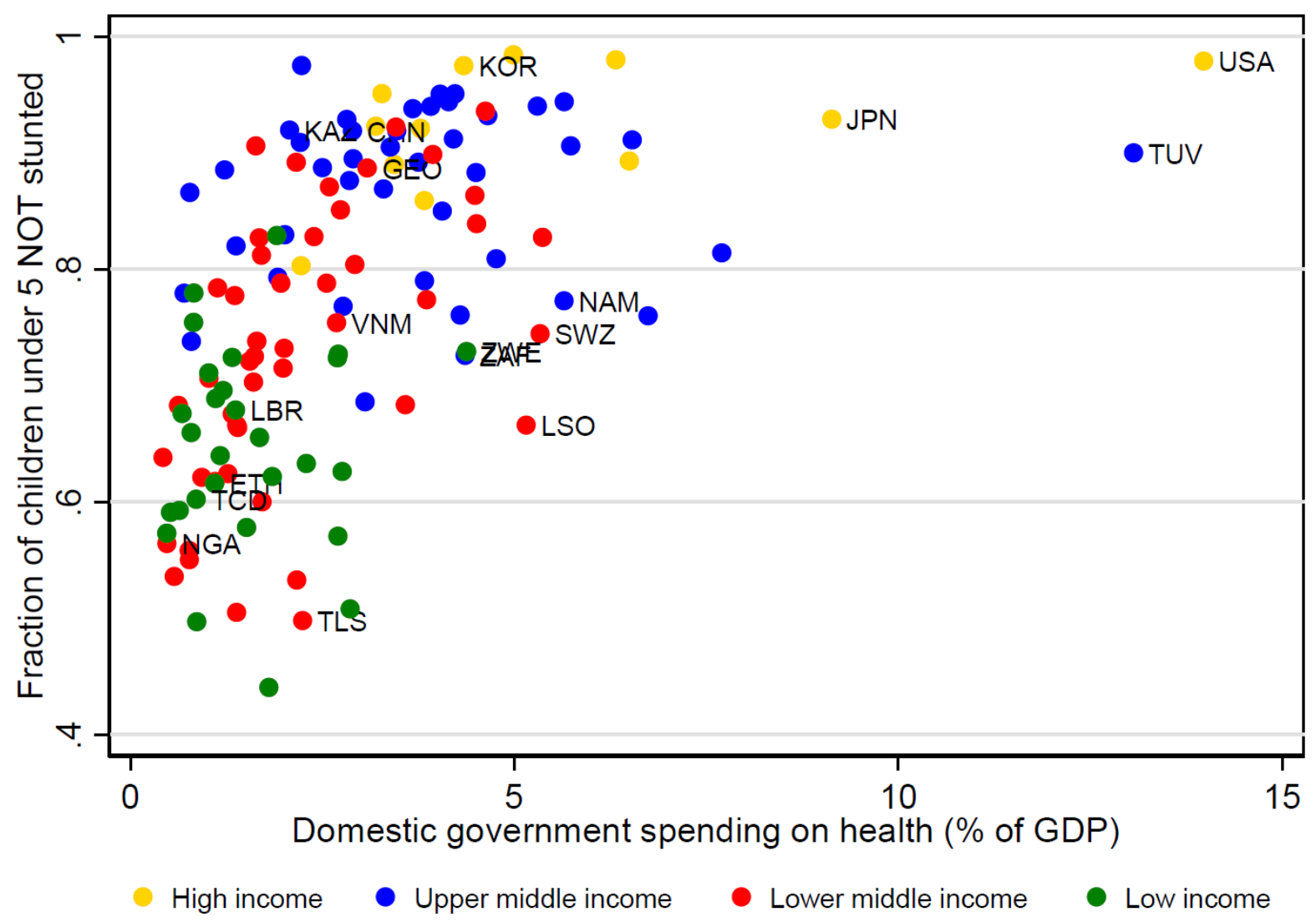

Source: Andrews et al. (2019), figure 13. License: CC BY 3.0 IGO.

Note: $\mathrm{CAN}=$ Canada ETH = Ethiopia; GEO = Georgia; JPN = Japan; KAZ = Kazakhstan; KOR = Republic of Korea; LBR = Liberia; LSO = Lesotho; NAM = Namibia; NGA = Nigeria; SWZ = Swaziland; TCD = Chad; TLS = Timor-Leste; TUV = Tuvalu; USA = United States; VNM = Vietnam; ZAF = South Africa; ZWE $=$ Zimbabwe.

${ }^{14}$ Watkins et al. (2020). Stenberg et al. (2017) provide comparable estimates. 
A focus on both improving efficiency, and raising revenues equitably, will help improve health outcomes (Lancet Commission on Investing in Health 2013, Smith and Nguyen 2013). There are two priorities. First, making health systems perform more efficiently, and with a greater emphasis on the quality of care; for instance, by creating effective multifunctional delivery platforms that can treat a range of health concerns and provide lifelong care. Second, raising financing in a manner that does not depress utilization or worsen outcomes, particularly among the disadvantaged. Broad institutional reforms are required to underpin both agendas.

Using information systems to capture and analyze relevant data on health processes and outcomes, and to transmit information to policymakers and the public in a timely, digestible fashion, is essential to effective policy making. Measurement is key to accountability and improvement, but available metrics do not capture much of what matters most to people, such as competent care, user experience, health outcomes, and confidence in the system (Lancet Global Health Commission 2018). Conversely, inputs such as medicines and equipment are commonly recorded, but are only weakly related to quality of care. Robust vital registries, trustworthy routine health-information systems, financial-protection indicators, and real-time measures of health facilities and populations are all prerequisites for good performance assessment. Investing in better measurement, in the institutions and professionals with the skills to generate and interpret data, including through new research, yields high returns.

Reforms will prove successful and sustainable only if underpinned by improved governance. Decision-making processes must be viewed as fair, encourage public involvement, ensure accountability in policy development and implementation, and track progress (Kurowski 2018). Accountability requires that decisions be transparent and justified by legitimate criteria. At the same time, public-health officials across all levels of government should enjoy appropriate autonomy and well-aligned incentives. Mechanisms that both allow beneficiaries to appeal decisions, and which review them based on new information, strengthen the accountability link between service providers and beneficiaries.

\section{B. Building a high-performing health system}

A policy priority, in health as in education, is to obtain greater value-for-money through systems reform, rather than just raising expenditure. Current health-care service delivery structures are often low-value and high-cost. They over-provide potentially clinically ineffective treatments in inappropriate settings, and under-provide more effective treatments (Lancet Global Health Commission 2018). Low-quality care raises costs for both governments and households and reduces health gains. Efficiency and resilience to crises can be significantly boosted by complementary reforms focused on five key areas (Somanathan et al. 2015, Kruk et al. 2015, Maeda et al. 2014). 
Moving away from hospital-centric structures, by increasing the availability, effectiveness, and quality of primary care

High-quality primary care, including preventive care, remains one of the most efficient and cost-effective ways to achieve UHC (UN 2019). Such care is accessible, can address more than 80 percent of a person's lifetime health needs, and is affordable: many interventions cost less than $\$ 100$ per additional healthy life-year (McKinsey Global Institute 2020). Prevention in particular is often more clinically- and cost-effective than treatment. The COVID-19 pandemic reemphasized the need to invest in these services, with strong frontline delivery systems. In LICs and LMICs, priorities include perinatal care; childhood immunizations and nutrition (section IV provides case studies of reductions in child stunting); infectious disease control programs for HIV/AIDS, tuberculosis, and malaria; and community-based health promotion and disease prevention, including sanitation. Upper-middle-income and high-income countries should focus on reducing the growing NCD burden and promoting healthy longevity. This involves a lifecourse perspective to health care, both reducing behavioral risk factors at all ages, and increasing the early detection and management of diseases.

Primary care should tackle a greater range of low-acuity conditions; hospitals should only provide complex services that need advanced expertise, with clear pathways for referral and consultation ("right-placing care"). Reorganizing services so that care is provided at the right level, and available resources are optimized, is in the interests of both health systems and patients. Better health is often incorrectly attributed to more consultations, admissions, drugs, and procedures. Meanwhile, too little attention is paid to prevention, early diagnosis and treatment, and control of conditions. ${ }^{15}$ Once a diagnosis is made, care is rarely coordinated across provider levels, resulting in service duplication and lack of continuity. Often, health care is sought too late, leading to high-cost treatment in expensive acute-care hospitals. The lack of effective referrals, gatekeeping, and post-discharge care contributes to avoidable or unnecessarily long admissions that prove costly. ${ }^{16}$ For instance, with better patient-centric care models, primary-care centers would provide long-term care for chronic conditions; conversely, some labor and delivery services could be relocated to hospitals. Right-placing care presupposes a significant strengthening of primary care, with support from community health workers: currently, primary care is often rudimentary and low-quality (see below), and the public therefore bypasses it.

\footnotetext{
${ }^{15}$ Many developing countries are characterized by hypertension that is rarely brought under control; limited programs to prevent and treat substance abuse, including smoking; little emphasis on weight management; little testing for high cholesterol; low screening rates for the most treatable cancers (breast, cervical, colon, and prostate); and rare flu vaccinations for the elderly (Lancet Global Health Commission 2018).

${ }^{16}$ Many developing countries have high rates of hospitalization for hypertension, a condition that should be controlled at lower levels of care.
} 
Pandemics including COVID-19 have also highlighted the need for stronger, more resilient, and equitable public-health systems. Priorities include:

- $\quad$ Strengthening national and global disease-surveillance systems, by boosting the ability to collect, analyze, and interpret relevant data from public and private providers, including primary-care practitioners. This will enable authorities to better plan, implement, and evaluate actions to prevent and control disease outbreaks (Revenga and Galindo 2020). Effective disease surveillance is feasible even in low-resource settings, based on standardized sets of symptoms.

- $\quad$ Building early-response capacity. Responsiveness calls for preparedness before outbreaks occur. This requires years of planning and investing in the institutional and technical capacity to rapidly step in and manage crises (Fernandes 2020). Other ingredients include teams with decision-making autonomy to respond swiftly, and emergency-procurement procedures in the event of shortages.

- Ensuring a "whole-of-society", multi-sectoral approach. Local leaders and community volunteers are critical to effective community outreach, social-services delivery, and support for quarantined households (WHO 2020). Partnerships with the private sector are equally important: in many developing countries, private facilities are the first health-care contact point and deliver most services. With most pandemics being of zoonotic origin, closer coordination between the health and agriculture sectors is instrumental to preventing future outbreaks. Boosting public health involves complementary investments in infrastructure, including safely managed sanitation, clean drinking water, and handwashing facilities.

\section{Improving quality of care in treating both chronic and acute illness}

The care that people receive is often inadequate, with disadvantaged groups faring the worst. High-quality care involves thorough assessment, detection of asymptomatic and co-existing conditions, accurate diagnosis, appropriate and timely treatment, referral when needed for hospital care and surgery, and the ability to follow the patient and adjust treatments as needed. But lowquality care is common across countries and conditions. Audits of patient-provider encounters find a high frequency of incorrect diagnosis or treatment, even for common, serious conditions including tuberculosis, pneumonia, myocardial infarction, and newborn asphyxia (WHO, World Bank, and OECD 2018). There are major system-level deficiencies in infection control, prevention, and continuity and timeliness of care. Patients frequently complain about poor communication by providers, lack of attention and respect, and excessively short consultations. Sometimes, providers are simply absent; in Togo and Uganda, almost half of primary-care providers were absent from their health facility in 2013 (Andrews et al. forthcoming). And worse health outcomes for the disadvantaged frequently reflect inequalities in the quality of care, rather than in access or financial coverage. Even where coverage for some health services is seemingly equal, the effective coverage, with services of quality sufficient to achieve the expected health 
gains, often remains highly unequal. ${ }^{17}$ Patients may seek higher quality by bypassing designated health providers, but this will force them to pay in full for services and increase the incidence of catastrophic expenditures. In LMICs, poor-quality care is now a larger barrier to reducing mortality than insufficient access. Quality of care will become an even more important driver of population health as the burden of disease shifts to more complex conditions such as NCDs.

Structural, foundational change is needed to improve the quality of care, and ensure that it is evidence-based and both clinically- and cost-effective. Health-system leaders should adopt a shared vision of quality care, backed by a clear quality strategy, incorporating multiple, complementary measures (Lancet Global Health Commission 2018):

- Boosting provider skills, through rigorous pre-service education and early clinical exposure, specialty training, and an emphasis on continuous, active, problem-based learning. Better performance measurement, linked to professional recognition or compensation, may improve motivation (see below).

- Increasing management capacity at all levels, including through training programs and adoption of electronic health records.

- Strengthening regulation and accountability, including through clinical treatment protocols, inspector training, and legal-redress mechanisms. In hospitals, specific reforms may include dedicated quality-of-care committees, using checklists for supervision and inventory-control purposes, and auditing the medical register routinely or after deaths.

Coordination with the private sector and other public sectors, such as education and infrastructure, will help boost outcomes. Partnerships with civil society, for instance through community monitoring programs (Björkman and Svensson 2009) and informational campaigns (Pandey et al. 2007), will increase accountability and raise user satisfaction. At the same time, quality improvements may require increased inputs, including staffing and physical resources. Primarycare facilities in lower-income countries, especially in disadvantaged communities, often lack access to clean water, electricity, and improved toilets; refrigerator temperatures may not comply with standards for storing vaccines.

\section{Reforming mechanisms for paying health-care providers}

In many high- and some middle-income countries, the incentives embedded in providerpayment systems have encouraged physicians to overprovide services, driving up costs. This applies especially to fee-for-service systems without budget caps or other cost-containment

\footnotetext{
${ }^{17}$ In the Democratic Republic of Congo, coverage for antenatal care, defined as attending a consultation, does not vary significantly by household wealth. But effective coverage, including appropriate tests, treatments, and communication, remains much more unequal (Fink et al., forthcoming).
} 
measures; these reward quantity over quality, and discourage prevention and patient education. Experience with payment reforms points toward reimbursing hospitals on the basis of expected costs for clinically defined episodes of care, and reimbursing primary-care providers at least partly through a "lump sum" per patient. Possibly, measured risk factors could be used as a basis for reimbursement to incentivize physicians through pay-for-performance schemes. In all cases, appropriate incentives must also ensure quality of care. Depending on the institutional setting, measures to boost competition among hospitals, physicians, pharmacists, and/or insurance providers, within a strong government regulatory framework, may help reduce costs and/or raise quality (Propper 2018, Gaynor and Town 2011).

Most LICs and LMICs, conversely, are struggling with under-provision of essential services; incentives are needed to boost access, utilization, and quality, particularly for the disadvantaged. Uptake remains very low among the disadvantaged groups that would benefit most from such services, including family planning and maternal and child health. Here, some level of fee-for-service can be beneficial. Again, pay-for-performance schemes can be highly clinically- and cost-effective in improving delivery of targeted services (Kandpal 2016). They may also promote general health-system strengthening, and increase efficiency and accountability, through more active supervising and monitoring, more quantifiable involvement with communities, and increased health-worker satisfaction. Such supply-side incentives work best when combined with demand-side financing measures to boost health-seeking behavior, including cash or in-kind transfers, transportation, and community outreach.

\section{Improving the price and availability of critical medical products}

Inefficiencies in purchasing pharmaceuticals result in high prices for drugs, driving up costs for governments and users. The price of common, off-patent statins (cholesterol-lowering drugs critical for pharmacological management of cardiovascular disease) varies significantly across countries. For example, in Vietnam, a highly decentralized and complex procurement system, involving more than 1,000 entities, results in wide differentials in medicine prices across facilities (Somanathan et al. 2015). Purchasing strategies used to reduce drug prices include:

- $\quad$ Therapeutic reference pricing: purchasers set fixed reimbursement levels for the price of drugs by referencing a base drug within that therapeutic class.

- $\quad$ Risk-sharing arrangements for high-cost drugs, such as price-volume arrangements where the manufacturer pays for any volume over the agreed threshold.

- $\quad$ Sole-source tendering, where the winning bidder is the sole supplier for a fixed term.

- $\quad$ Bulk-buying of drugs, where a lead agency consolidates purchases by different entities.

Building diversified, resilient global medical supply chains remains critical. The COVID-19 crisis underscored existing vulnerabilities, generating shortages and potentially excessive pricing for key medical products (OECD 2020b). Suppliers struggled to meet growing global demand for 
personal protective equipment, ventilators, and other supplies, including because of severe disruptions to global supply chains. Developing countries remain vulnerable to partner countries' restrictions on exports of medical products, also reflecting some exporting countries' high global market share in specific products (Espitia et al. 2020).

Accelerating technological transformation, while prioritizing among available interventions and technologies

Continued innovation in health-care delivery and medical technology, underpinned by global cooperation to ensure equitable access, has proven essential to improving long-run outcomes. Telemedicine, including virtual care platforms and digital monitoring, is proving an increasingly cost-effective delivery mechanism. For many NCDs, including some cancers, mental-health disorders, and dementia, more in-depth knowledge is required on the underlying biology; and further innovation in medicines, procedures, medical devices, and delivery models will help improve the range and availability of treatments (McKinsey Global Institute 2020). For many promising technologies, small-scale pilots and applications already exist; many are preventive in nature and enabled by digital technology. The COVID-19 pandemic also exposed the need to bolster research into infectious diseases, including therapeutics and vaccines, even before an outbreak occurs. Digital technology and machine learning can assist with pandemic containment and mitigation processes, including the diagnosis and prognosis of patients. Developing countries, given resource constraints, will need to partner with the international community and private sector to leverage the latest technology. The global deployment of new vaccines requires significant financing and the coordinated use of financial instruments including grants, concessional loans, and advance market commitments (Yamey et al. 2020).

However, prioritizing which new technologies are adopted is vital to controlling healthexpenditure growth. Many OECD countries have introduced explicit prioritization systems, through health-technology assessments (HTA) that systematically and transparently assess the value-for-money of new technologies, devices, and procedures. Developing the capacity to undertake HTA is costly and time-consuming. Developing countries could start by using the findings from more established HTA agencies to inform prioritization.

\section{Efficient, equitable financing}

Financing measures to support UHC should not burden the disadvantaged and further depress their low health-services utilization rate. One option: publicly financed insurance could cover only essential health-care interventions, which disproportionately benefit the poor, with no user fees. Alternatively, a larger benefit package could be funded through a range of financing mechanisms, including tax revenue but also mandatory insurance premiums and/or copayments, with the poor exempted from all payments (Lancet Commission on Investing in Health 2013). This latter approach assumes sufficient administrative capacity to identify the poor, and levy payments from the non-poor. In either case, taxation of tobacco, alcohol, and other harmful 
substances, and the removal of fossil-fuel subsidies that encourage pollution, can both raise revenue and directly curb NCDs, with disproportionate health benefits for the poor.

Less reliance on contributory funding mechanisms, and de-linking entitlements to coverage from users' direct health-insurance contributions and employment status, can often help broaden health coverage. General revenues can instead be used to fully cover contributions, at least for those who cannot afford to pay or whose contributions would be administratively difficult to collect (the approach being adopted in Indonesia, the Philippines, Thailand, and Vietnam). Historically, it has proved extremely difficult to enroll through contributory means the poor and other vulnerable groups, such as informal-sector workers (Bitran 2014); even small out-of-pocket payments depress utilization rates among disadvantaged groups. Premiums, even when apparently low, remain unaffordable for many. The very process of having to enroll in contributory schemes and/or apply for subsidies is often associated with administrative complexities that create additional barriers to access (Alfers 2013, Barasa et al. 2017). And there is widespread lack of information about, or trust in, the benefits of enrollment (Dartanto et al. 2016). As a result, partial subsidies, even when combined with assistance in enrolling (such as information and reminders), have proven less effective than anticipated; often they have resulted in adverse selection, as only those with high anticipated health needs were willing to pay to enroll (World Bank 2019c). All this is a particular concern in regions, such as Africa or Asia, where the informal sector remains large. However, there are examples of success. Among the very few countries that have been successful in enrolling all or most informal-sector workers are Thailand (100 percent premium subsidy) and China (90 percent premium subsidy under the National Cooperative Medical Scheme). In the case of pharmaceuticals, and especially outpatient drugs (for instance, betablockers for heart disease, and antiretroviral and anti-tuberculosis drugs), out-of-pocket payments may reduce adherence to treatment regimens and increase downstream systemwide costs owing to more hospitalizations.

Reducing fragmentation of health-insurance schemes can deliver important benefits. In many countries, current arrangements are often fragmented, inequitable, inefficient, and costly. Governments frequently initiate coverage with the formal sector, providing privileged access to a politically influential group (Somanathan et al. 2015). Those initially covered resist extending the same entitlements to the rest of the population, resulting in multiple insurance schemes being created with varying levels of coverage. ${ }^{18}$ Such schemes have proved politically difficult to integrate, since any such measure would redistribute resources across organized interest groups. However, multiple risk pools are both inequitable and inefficient. Moreover, the relatively generous benefits for the formal sector threaten cost-containment. That said, in countries with fledgling schemes, fragmentation may initially be inevitable. Efforts to expand health coverage

\footnotetext{
${ }^{18}$ In Mexico, prior to deep reforms, per-capita funding for social health-insurance beneficiaries was 6 times larger than for those dependent on national health services. Coverage for hypertension control was 20 percentage points higher among the former than among the latter group.
} 
may have to rely on a variety of financing sources and coverage packages. Even here, it remains important to ensure that everyone is entitled to a basic coverage level.

\section{REASONS FOR OPTIMISM: CASE STUdIES OF SUCCESSFUL REFORM ${ }^{19}$}

The experience of countries at all development levels demonstrates that significant progress is possible. Countries can draw on systematic knowledge about what works at the micro level and how to sustain system-wide improvements. Any given intervention may not pay off in all contexts, and successful interventions cannot be imported wholesale into new contexts. Nonetheless, countries can use them as starting points for their own innovations. We now present some illustrative case studies.

\section{A. Overall human-capital development}

Singapore, Morocco, Ghana, and the Philippines have all experienced, to varying degrees, notable human-capital improvements. Singapore has built a world-class education system, which balances creativity with the increasing need for analytical skills and teamwork. Life expectancy is among the highest and infant mortality among the lowest in the world. Morocco has experienced remarkable gains in both urban and rural primary enrollment. Child and maternal mortality have declined sharply, and most children are fully immunized. In Ghana, primary enrollment has increased sharply, with an influx of students from disadvantaged families, and child stunting, an indicator of chronic malnutrition, has almost halved. The Philippines has seen a dramatic expansion in school enrollment since the 1970s, but quality remains an issue.

Successful reforms in these countries have adopted a "whole-of-society" approach, involving:

- Coordination - between sectoral programs, and among different levels and branches of government.

- Continuity — sustaining effort across many political cycles.

- $\quad$ Evidence - building an evidence base to improve and update human-capital strategies.

Multisectoral strategies that also involve local actors are more likely to succeed, particularly in lower-income countries. Integrated efforts are especially beneficial in countries with limited public funds and technical and administrative capacity, which cannot afford to waste resources. In the Philippines, successive governments have adopted multi-sectoral programs, promoted integrated approaches, and encouraged greater participation by stakeholders in service delivery. A conditional cash transfer program integrates human-capital development with poverty reduction. It assists chronically poor households with children under 14 living in deprived areas.

\footnotetext{
${ }^{19}$ This section draws on World Bank (2018, 2019b, 2020 section 2.3, 2020c).
} 
Beneficiaries must undertake activities to improve their children's health and education, including prenatal checkups, pediatric visits, and regular school attendance. Multiple agencies, including state-owned banks, implement the program; efforts are coordinated with regional offices. Local service providers, including school principals and midwives, verify household compliance with program conditions. This enables the program to reach targeted households across hundreds of islands. A range of other policies, including poverty-reduction efforts, recognize that humancapital development is affected by multiple factors including clean air, a safe water supply, and sanitation services.

Ghana's success in reducing stunting also largely reflects a multi-sectoral approach. The schoolfeeding program brings together community leaders with local caterers and farmers to supply food to children. The program is linked to local agricultural development, especially smallholder production, helping to create new markets for locally grown food. Monitoring and evaluation rely on local head-teachers and caterers. Likewise, initiatives to improve water sanitation and hygiene in schools have boosted both health and education indicators. Morocco has developed a variety of social safety nets that cover multiple sectors and support a range of human-capital outcomes. Complementary programs aim to achieve universal education and reduce school drop-out, especially in rural areas and among girls, by providing school bags, subsidized transport, food, and school supplies for students. There are also programs for disabled individuals, social protection centers, and centers for training and education that support disadvantaged girls. A range of subnational committees help select development projects and monitor implementation. Singapore has integrated health and education goals into many facets of government. Urban planning stresses health outcomes, since these are affected by all aspects of urban life-including housing, water supply, air quality, waste disposal, and traffic. Coordination between government institutions enables the country to track trends in labor demand, and match the skills taught in the education system with market needs.

Continuity of commitment and effort over successive governments is key to growing human capital, a process which can take generations. Such continuity is easier when a country enjoys political stability and consensus. In Ghana, a stable multiparty democracy since 1992, successive governments from different parties have made human capital a priority, with broad social support. By contrast, in the Philippines, while successive administrations did adopt strategies to build human capital, they did not make the sustained effort to build the capacity and governance necessary to implement these strategies. And although Morocco showed sustained political commitment to education, this commitment did not extend to other policies critical to improving human capital.

Adequate, sustainable funding is crucial, as is using resources efficiently. Singapore ensured that expenditures were managed effectively, including through severe sanctions for corruption. In Ghana, domestic resource mobilization enabled a large expansion of primary-care insurance coverage, including prenatal and postnatal care, vaccinations, and health and nutrition education. Inequity in access was reduced by exempting disadvantaged groups from premiums. By contrast, the Philippines have generally failed to provide adequate financing, leading to understaffed, 
overcrowded clinics and schools, underpaid providers, inadequate infrastructure, and a lack of administrative and technical capacity, especially at the local level. Weak governance led to widespread fraud in textbook distribution, theft of funds or supplies, and ghost workers in municipal health facilities. All this particularly affects low-income households and more remote regions, which lag in terms of access.

Reliable, timely administrative and survey data is critical to effective policy design and implementation. Singapore's digital infrastructure, tech-savvy administrators, and experienced teachers form a robust data-collection system that generates critical real-time information on schools, training institutions, and skills in demand. Policymakers use these data to assess school and student performance, control costs, help managers and teachers to make decisions at every level, and enable workforce planning. In Ghana, national poverty statistics and a food security and vulnerability analysis established that school-feeding programs were not effectively reaching vulnerable groups. The data were combined to refine targeting and reduce leakages. The Philippines implemented a data-driven system that supported a range of social programs and enabled effective beneficiary targeting. Conversely, in Morocco, limited data has prevented evaluation and stymied improvements to the conditional cash transfer program.

\section{B. Successes in education}

Several countries have implemented reforms that led to sustained improvements in learning. Their success reflects varying combinations of the approaches discussed earlier: new pedagogical methods, ways to ensure that students and teachers are motivated, new approaches to school management, and technologies to enhance learning.

- $\quad$ Korea had very low literacy rates in the 1950 s, but by 1995 was performing at the highest levels on international assessments. It first prioritized universal basic education and vocational learning, to supply the skilled workers necessary for economic development. It then targeted universal secondary education, and rapidly expanded higher education and private education as the economy became more knowledge-based. This sequential educational expansion helped solve the constraint of limited resources.

- $\quad$ Finland's major education reform in the 1970s increased quality and equity at reasonable cost, helping it top the 2000 PISA assessment. Key measures included investments in teacher education, and a major overhaul of the curriculum and assessment system to ensure access to a "thinking curriculum" for everyone.

- Vietnam and Shanghai today show that it is possible to perform far better than income levels would predict. A generation ago, Vietnam was far from even universal primary schooling, but today learning poverty has been virtually eliminated, and secondary schools achieve PISA scores on par with Germany's. National strategies focused first on free primary education, particularly for the disadvantaged. Greater attention was then given to vocational education to meet the demand for trained workers, particularly in key sectors. 
New pre- and in-service training programs were initiated at massive scale for all teachers. Shanghai topped the 2012 PISA rankings, as policies ensured every classroom had a prepared, supported, and motivated teacher, and key system elements, including a wellfocused curriculum, were all aligned toward learning (Liang et al. 2016).

Even in countries stuck in low-learning traps, some teachers, schools, and regions successfully promote learning. In the state of Ceará in Brazil, the municipality of Sobral in 2005 ranked $1,366^{\text {th }}$ among 5,570 Brazilian municipalities on the country's synthetic indicator of education quality. A decade later, it ranked first in the country in both primary and lowersecondary education, achieving learning outcomes comparable to world-class education systems (Cruz and Loureiro 2020, World Bank 2019). This success occurred despite a relatively low GDP per capita and a high student-to-teacher ratio, suggesting high system efficiency. It reflected a focus on four pillars: continuous use of student assessments; a focused curriculum with a clear learning sequence and prioritization of foundational skills; developing a pool of well-prepared and motivated teachers; and autonomous and accountable school management, with school principals appointed through a meritocratic technical selection process. Underlying this, state political leaders insulated education from partisan politics.

\section{Successes in health care}

Case studies confirm that improving health outcomes requires cross-cutting, "whole-ofsociety" solutions; chronic malnutrition provides a clear example. Successful health reform typically demands that governments "put forward a multi-sectoral approach for health at all government levels, to address NCD risk factors and underlying determinants of health comprehensively and decisively" (UN 2011). Multiple interventions from both within and outside the health sector are required to tackle chronic malnutrition, or stunting, among children, with its large, permanent effects on health and cognitive development (Bhutta et. al. 2020). Peru, in less than a decade, more than halved its rate of stunting among children under five. This success reflected a shift in focus away from simply providing food assistance to poor households, and towards a multi-sectoral approach to nutrition that included better provision of public services; cooperation between multiple national ministries, regional and municipal governments, and NGOs; and improved incentives for government and households (Marini et al. 2017). Government agencies were given monetary incentives to expand health and nutrition services, especially for the most vulnerable. Conditional cash transfers to poor households, increased health-insurance coverage, and public-outreach campaigns boosted demand for these health and social services. Comprehensive data-monitoring systems and strong local accountability mechanisms enhanced program effectiveness. And persistent lobbying by civil society convinced four successive governments to continue the effort. A similar multi-sectoral approach enabled Senegal to reduce sharply child stunting, anemia, and obesity, and chronic malnutrition (Ruel-Bergeron 2018).

The benefits of multi-sectoral strategies are evident for child development more generally, and for public health. Chile enjoyed remarkable progress in child development through the integrated deployment of a broad range of health, nutrition, education, and social programs and 
benefits, coordinated by a national-level body and municipalities. Direct transfer funding agreements, and the systematic collection of data for program management, promoted local accountability (World Bank 2018b, BMJ 2018, Clarke et al. 2018). Similarly, tobacco and alcohol control require coordination across sectors such as finance (taxation strategies), agriculture (crop substitution programs), and preventive care (tobacco cessation programs). Such coordination is easiest with formal inter-agency cooperation agreements (Lencucha et al. 2015). Agreements in these areas, as in nutrition policy, must be structured to avoid regulatory capture by private interests (Carey et al. 2015).

\section{CONCLuSion}

More and better investments in education and health can help realize their full promise as drivers of poverty elimination and inclusive growth. Education and health are basic human rights. Done right, they yield huge payoffs, improving social outcomes in many spheres of life. For individuals and families, they expand economic opportunities and agency. For societies, they promote social mobility and make institutions function more effectively. They increase a country's resilience, and allow it to take advantage of technological change or economic integration. These benefits depend on the skills that students acquire and on the population's health, not just on the number of years in the classroom or total health-care spending.

The COVID-19 pandemic presents an opportunity to "build back better", creating stronger, more resilient, and more inclusive education and health systems. There is an opening to mobilize a consensus for tackling existing inefficiencies and inequities. Most households now share the long-standing concerns of the vulnerable: having access to safe, good schools and health care. The pandemic galvanized new actors across the community—parents, community health and social welfare organizations, media and technology companies, local nonprofits and businessesto work together with schools and health facilities to support learning and good health (World Bank 2020b, Vegas and Winthrop 2020).

Significant progress is possible with a commitment to spending not only more, but better. A commitment to improving delivery systems by strengthening accountability and incentives. A commitment to an evidence-based, whole-of-society approach to policymaking and action. A commitment to reform that is maintained across political cycles. Countries at every income level have shown such commitment, and now reap the rewards. 


\section{REFERENCES}

Adelman, M., and R. Lemos. 2020. Managing for Learning: Measuring and Strengthening Education Management in Latin America and the Caribbean.

Al-Samarrai, S., P. Cerdan-Infantes, and J. Lehe. 2019. "Mobilizing Resources for Education and Improving Spending Effectiveness". World Bank Policy Research WP 8773.

Alfers, L. 2013. "The Ghana National Health Insurance Scheme: Barriers to Access for Informal Workers". WIEGO WP 30.

Andrabi, T., B. Daniels, and J. Das. 2020. "Human Capital Accumulation and Disasters: Evidence from the Pakistan Earthquake of 2005”. RISE WP 20/039.

Andrews, K., C. Avitabile, and R. Gatti. 2019. "Domestic Government Spending on Human Capital: A Cross-Country Analysis of Recent Trends". World Bank Policy Research WP 9033.

Andrews, K., R. Conner, R. Gatti, and J. Sharma. Forthcoming. "The Average Citizen's Experience with Primary Care: Levels and Distribution of Quality Care in 9 Countries in SubSaharan Africa”. World Bank Policy Research WP.

Andrews, M., L. Pritchett, and M. Woolcock. 2013. "Escaping Capability Traps through Problem Driven Iterative Adaptation (Pdia)". World Development.

2017. Building State Capability: Evidence, Analysis, Action.

Angrist, N., D. Evans, D. Filmer, et al. 2020. "How to Improve Education Outcomes Most Efficiently?". World Bank Policy Research WP 9450.

Angrist, N., P. Bergman, C. Brewster, and M. Matsheng. 2020b. "Stemming Learning Loss During the Pandemic: A Rapid Randomized Trial of a Low-Tech Intervention in Botswana". CSAE WP 2020-13.

Avitabile, C., R. D’Souza, R. Gatti, and E.W. Chapman. 2020. Insights from Disaggregating the Human Capital Index.

Banerjee, A., S. Cole, E. Duflo, and L. Linden. 2007. "Remedying Education: Evidence from Two Randomized Experiments in India”. Quarterly Journal of Economics.

Banerjee, A., R. Banerji, E. Duflo, et al. 2010. "Pitfalls of Participatory Programs: Evidence from a Randomized Evaluation in Education in India". American Economic Journal: Economic Policy. 
Banerjee, A., R. Banerji, J. Berry, et al. 2016. "Mainstreaming an Effective Intervention: Evidence from Randomized Evaluations of 'Teaching at the Right Level' in India'. NBER WP $\underline{22746 .}$

Barasa, E. W., N. Mwaura, K. Rogo, and L. Andrawes. 2017. "Extending Voluntary Health Insurance to the Informal Sector: Experiences and Expectations of the Informal Sector in Kenya". Wellcome Open Research.

Barber, S., S. O’Dougherty, L. Torres, et al. 2020. "Other Considerations Than: How Much Will Universal Health Coverage Cost?". Bulletin of World Health Organization.

Barrera-Osorio, F., and D. Filmer. 2016. "Incentivizing Schooling for Learning: Evidence on the Impact of Alternative Targeting Approaches". Journal of Human Resources.

Bau, N., and J. Das. 2017. "The Misallocation of Pay and Productivity in the Public Sector: Evidence from the Labor Market for Teachers". World Bank Policy Research WP 8050.

Beasley, E., and E. Huillery. 2017. "Willing but Unable? Short-Term Experimental Evidence on Parent Empowerment and School Quality". World Bank Economic Review.

Bhutta, Z., N. Akseer, E. Keats, et al. 2020. "How Countries Can Reduce Child Stunting at Scale: Lessons from Exemplar Countries". American Journal of Clinical Nutrition.

Bell, B., R. Costa, and S. Machin. 2018. "Why Does Education Reduce Crime?”. CEPR DP $\underline{13162 .}$

Béteille, T., and D. Evans. 2019. "Successful Teachers, Successful Students: Recruiting and Supporting the World's Most Crucial Profession".

Bill and Melinda Gates Foundation. 2010. Learning about Teaching-Initial Findings from the Measures of Effective Teaching Project.

‥2020. COVID-19: A Global Perspective.

Bitran, R. 2014. Universal Health Coverage and the Challenge of Informal Employment: Lessons from Developing Countries. World Bank, Washington, DC.

Björkman, M., and J. Svensson. 2009. "Power to the People: Evidence from a Randomized Field Experiment on Community-Based Monitoring in Uganda". Quarterly Journal of Economics.

BMJ. 2018. "Scaling Up an Early Childhood Development Programme Through a National Multisectoral Approach to Social Protection: Lessons Learned from Chile Crece Contigo".

Bold, T., M. Kimenyi, G. Mwabu, et al. 2013. "Scaling up What Works: Experimental Evidence on External Validity in Kenyan Education". CGD WP 321. 
Bold, T., D. Filmer, M. Gayle, et al. 2017. "What Do Teachers Know and Do? Does It Matter? Evidence from Primary Schools in Africa”. World Bank Policy Research WP 7956.

Bouguen, A., D. Filmer, K. Macours, and S. Naudeau. 2013. "Impact Evaluation of Three Types of Early Childhood Development Interventions in Cambodia". World Bank Policy Research WP 6540.

Bruns, B., D. Filmer, and H. Patrinos. 2011. Making Schools Work: New Evidence on Accountability Reforms.

Bruns, B., and J. Luque. 2014. Great Teachers: How to Raise Student Learning in Latin America and the Caribbean.

Campos, J. E., B. Randrianarivelo, and K. Winning. 2015. "Escaping the 'Capability Trap': Turning 'Small' Development into 'Big' Development'. International Public Management Review.

Carey, R., M. Caraher, M. Lawrence, and S. Friel. 2015. "Opportunities and Challenges in Developing a Whole-of-Government National Food and Nutrition Policy". Public Health Nutrition.

Chisholm, L., and R. Leyendecker. 2008. "Curriculum Reform in Post-1990s Sub-Saharan Africa". International Journal of Educational Development.

Chong, A., and M. Gradstein. 2015. "On Education and Democratic Preferences". Economics and Politics.

Clarke, D., G. Cortés Méndez, and D. Vergara Sepúlveda. 2018. "Growing Together: Assessing Equity and Efficiency in an Early-Life Health Program in Chile". IZA DP 11847.

Cruz, R., and L. Loureiro. 2020. "Achieving World-Class Education in Adverse Socioeconomic Conditions: The Case of Sobral in Brazil".

Cunha, F., and J. Heckman. 2007. "The Technology of Skill Formation". American Economic Review 97 (2): 31-47.

D'Souza, R., R. Gatti, and A. Kraay. 2019. "A Socioeconomic Disaggregation of the World Bank Human Capital Index".

Darling-Hammond, L., A. Amrein-Beardsley, E. Haertel, and J. Rothstein. 2012. "Evaluating Teacher Evaluation". Phi Delta Kappan.

Darling-Hammond, L., M. Hyler, and M. Gardner. 2017. "Effective Teacher Professional Development". Learning Policy Institute. 
Dartanto, T., J. Rezki, W. Pramono, et al. 2016. "Participation of Informal Sector Workers in Indonesia's National Health Insurance System". Journal of Southeast Asian Economies.

De Ree, J., K. Muralidharan, M. Pradhan, and H. Rogers. 2017. "Double for Nothing? Experimental Evidence on the Impact of an Unconditional Teacher Salary Increase on Student Performance in Indonesia". Quarterly Journal of Economics.

Duflo, E., P. Dupas, and M. Kremer. 2011. "Peer Effects, Teacher Incentives, and the Impact of Tracking: Evidence from a Randomized Evaluation in Kenya". American Economic Review.

Espitia, A., N. Rocha, and M. Ruta. 2020. "Trade in Critical COVID-19 Products".

Evans, D., and F. Yuan. 2017. "The Economic Returns to Interventions that Increase Learning".

Fernandes, G. 2020. "Overhauling Health Systems". Finance \& Development.

Fink, G., E. Kandpal, and G. Shapira. Forthcoming. "Inequality in Quality of Health Services: Wealth, Content of Care, and Price of Antenatal Consultations in the Democratic Republic of Congo". Economic Development and Cultural Change.

Flabbi, L., and R. Gatti. 2018. "A Primer on Human Capital". World Bank Policy Research WP $\underline{8309}$.

Fryer, R. 2017. "Management and Student Achievement: Evidence from a Randomized Field Experiment". NBER WP 23437.

Garcia Jaramillo, S. 2020. "COVID-19 and Primary and Secondary Education: The Impact of the Crisis and Public Policy Implications for Latin America and the Caribbean". UNDP COVID19 Policy Document 20.

Gaspar, V., D. Amaglobeli, M. Garcia-Escribano, D. Prady, and M. Soto. 2019. "Fiscal Policy and Development: Human, Social, and Physical Investment for the SDGs". IMF Staff Discussion Note 19/03.

Gaynor, M., and R. Town. 2011. "Competition in Health Care Markets". In: Pauly, M., T. Mcguire, and P. Barros (eds). Handbook of Health Economics 2: Ch. 9.

Gertler, P., J. Heckman, R. Pinto, et al. 2014. "Labor Market Returns to an Early Childhood Stimulation Intervention in Jamaica". Science.

Global Education Evidence Advisory Panel. 2020. "Cost-Effective Approaches to Improve Global Learning".

Green, D. 2016. How Change Happens. Oxford University Press. 
Guseva, M., M. Nakaa, A. Novel, et al. 2008. "Press Freedom and Development".

Huang, Z., G. Phillips, J. Yang, and Y. Zhang. 2020. "Education and Innovation: The Long Shadow of the Cultural Revolution". NBER WP 27107.

IMF. 2017. IMF Fiscal Monitor: Tackling Inequality. October.

Jackson, C. 2020. "Does School Spending Matter? The New Literature on an Old Question". In:

Tach, L., R. Dunifon, and D. L. Miller (eds), Confronting Inequality: How Policies and Practices Shape Children's Opportunities.

J-PAL. 2018. "Teaching at the Right Level to Improve Learning".

․ 2019. "Evidence Review: Will Technology Transform Education for the Better?".

Kandpal, E. 2016. "Completed Impact Evaluations and Emerging Lessons from the Health Results Innovation Trust Fund Learning Portfolio".

Kraay, A. 2019. "The World Bank Human Capital Index: A Guide". World Bank Research Observer.

Kraft, M., D. Blazar, and D. Hogan. 2018. "The Effect of Teacher Coaching on Instruction and Achievement: A Meta-Analysis of the Causal Evidence". Review of Educational Research.

Kruk, M., M. Myers, S.T. Varpilah, and B. Dahn. 2015. "What Is a Resilient Health System? Lessons from Ebola". Lancet.

Kurowski, C. 2018. "Equity on the Path to UHC: Deliberate Decisions for Fair Financing".

Lancet Commission on Health and Climate Change. 2015. "Health and Climate Change: Policy Responses to Protect Public Health". Lancet.

Lafortune, J., J. Rothstein, and D. W. Schanzenbach. 2018. "School Finance Reform and the Distribution of Student Achievement". American Economic Journal: Applied Economics.

Lancet Commission on Investing in Health. 2013. "Global Health 2035: A World Converging Within a Generation". Lancet.

Lancet Global Health Commission. 2018. "High-Quality Health Systems in the Sustainable Development Goals Era: Time for a Revolution". Lancet Global Health.

Lassibille, G. 2016. "Improving the Management Style of School Principals: Results from a Randomized Trial". Education Economics.

Lavinas, L., and A. Veiga. 2013. "Brazil's One Laptop Per Child Program: Impact Evaluation and Implementation Assessment". Cadernos de Pesquisa 43(149): 542-569. 
Lencucha, R., J. Drope, and J. Chavez. 2015. "Whole-of-Government Approaches to NCDs: The Case of the Philippines Interagency Committee-Tobacco". Health Policy and Planning.

Liang, X., H. Kidwai, and M. Zhang. 2016. How Shanghai Does It: Insights and Lessons from the Highest-Ranking Education System in the World.

Lustig, N., G. Neidhöfer, and M. Tommasi. 2020. "Short and Long-Run Distributional Impacts of Covid-19 in Latin America". CEQ WP 96.

Lyytinen, H., E. Ojanen, J. Jere-Folotiya, et al. 2019. "Challenges Associated with Reading Acquisition in Sub-Saharan Africa: Promotion of Literacy in Multilingual Contexts”. In: Spaull, N., and J. Comings (eds), Improving Early Literacy Outcomes.

Maeda, A., E. Araujo, C. Cashin, et al. 2014. Universal Health Coverage for Inclusive and Sustainable Development: A Synthesis of 11 Country Case Studies.

Mansuri, G., and V. Rao. 2012. Localizing Development: Does Participation Work?

Marini, A., C. Rokx, and P. Gallagher. 2017. Standing Tall: Peru's Success in Overcoming its Stunting Crisis.

McCoy, D.C., E. Peet, M. Ezzati, et al. 2016. "Early Childhood Developmental Status in Lowand Middle-Income Countries: National, Regional, and Global Prevalence Estimates Using Predictive Modeling". PLOS Medicine.

McKinsey Global Institute. 2020. Prioritizing Health: A Prescription for Prosperity.

Mizala, A., and B. R. Schneider. 2012. "Negotiating Education Reform: Teacher Evaluations and Incentives in Chile (1990-2010)". Governance.

Muralidharan, K., A. Singh, and A. Ganimian. 2019. "Disrupting Education? Experimental Evidence on Technology-Aided Instruction in India". American Economic Review.

Nannyonjo, H. 2017. Building Capacity of School Leaders : Strategies that Work-Jamaica's Experience.

O'Donnell, O., E. Van Doorslaer, and T. Van Ourti. 2014. "Health and Inequality". In: Atkinson, A., and F. Bourguignon (eds), Handbook of Income Distribution 2B.

OECD. 2020. The Economic Impacts of Learning Losses.

. 2020b. Exploitative Pricing in the Time of COVID-19. 
Pandey, P., A. Sehgal, M. Riboud, et al. 2007. "Informing Resource-Poor Populations and the Delivery of Entitled Health and Social Services in Rural India: A Cluster Randomized Controlled Trial”. JAMA.

Patel, D., and J. Sandefur. 2020. “A Rosetta Stone for Human Capital”. CGD WP 550.

Popova, A., D. Evans, and V. Arancibia. 2016. "Training Teachers on the Job: What Works and How to Measure It". World Bank Policy Research WP 7834.

Popova, A., D. Evans, M. Breeding, and V. Arancibia. 2019. "Teacher Professional Development Around the World: The Gap Between Evidence and Practice". CGD WP 517.

Prestinaci, F., P. Pezzotti, and A. Pantosti. 2015. "Antimicrobial Resistance: A Global Multifaceted Phenomenon". Pathogens and Global Health.

Propper, C. 2018. "Competition in Health Care: Lessons from the English Experience". Health Economics, Policy and Law.

Rajkumar, A., and V. Swaroop. 2008. "Public Spending and Outcomes: Does Governance Matter?". Journal of Development Economics.

Revenga, A., and J. Galindo. 2020. "Responding to Global Systemic Shocks: Applying Lessons from Previous Crises to Covid-19".

Robinson, V., C. Lloyd, and K. Rowe. 2008. "The Impact of Leadership on Student Outcomes: An Analysis of the Differential Effects of Leadership Types". Educational Administration Quarterly.

Rossi, F. 2019. "Human Capital and Macro-Economic Development: A Review of the Evidence". World Bank Policy Research WP 8650.

Ruel-Bergeron, J. 2018. The Case for Investment in Nutrition in Senegal.

Sabarwal, S., D. Evans, and A. Marshak. 2014. "The Permanent Input Hypothesis: The Case of Textbooks and (No) Student Learning in Sierra Leone". World Bank Policy Research WP 7021.

Save the Children. 2020. "Protect a Generation: The Impact of COVID-19 on Children's Lives".

Schady, N., J. Behrman, M. Araujo, et al. 2015. "Wealth Gradients in Early Childhood Cognitive Development in Five Latin American Countries". Journal of Human Resources.

Schleicher, A. 2018. World Class: How to Build a 21 $1^{\text {st_Century School System. }}$

Shonkoff, J., and P. Fisher. 2013. "Rethinking Evidence-Based Practice and Two-Generation Programs to Create the Future of Early Childhood Policy". Development and Psychopathology. 
Smith, O., and S. Nguyen. 2013. Getting Better: Improving Health System Outcomes in Europe and Central Asia.

Snilstveit, B., J. Stevenson, R. Menon, et al. 2016. The Impact of Education Programmes on Learning and School Participation in Low- and Middle-Income Countries: A Systematic Review Summary Report. International Initiative for Impact Evaluation (3ie).

Somanathan, A., C. Bredenkamp, E. Pambudi, and A. Tandon. 2015. Macrofiscal Implications of Achieving Universal Health Coverage in East Asia and Pacific, in: World Bank, East Asia and Pacific Economic Update, April.

Stenberg, K., O. Hanssen, T. Tan-Torres Edejer, et al. 2017. "Financing Transformative Health Systems towards Achievement of the Health Sustainable Development Goals". Lancet Global Health.

Suryadarma, D. 2012. "How Corruption Diminishes the Effectiveness of Public Spending on Education in Indonesia”. Bulletin of Indonesian Economic Studies.

UHC2030. 2020. "Living with COVID-19: Time to Get Our Act Together on Health Emergencies and UHC".

UN. 2011. Political Declaration of the High-Level Meeting of the General Assembly on the Prevention and Control of Non-Communicable Diseases.

. 2019. Universal Health Coverage (UHC): Fact Sheet.

—. 2020. The Sustainable Development Goals Report: Good Health and Well-Being. 2020b. Education During COVID-19 and Beyond.

UNDP. 2020. "Coronavirus Versus Inequality".

UNESCO. 2020. "Out of School Children and Youth".

UNICEF. 2020. COVID-19: Are Children Able to Continue Learning During School Closures?

Vegas, E., and R. Winthrop. 2020. "Beyond Reopening Schools: How Education can Emerge Stronger than Before COVID-19".

Watkins, D., D. Jamison, A. Mills, et al. 2017. "Universal Health Coverage and Essential Packages of Care". In: Jamison, D., H. Gelband, S. Horton, et al. (eds). Disease Control

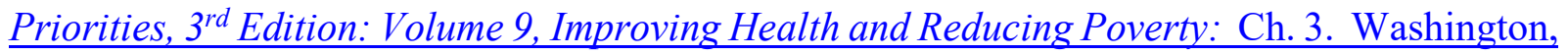
DC: World Bank. 
Watkins, D., J. Qi, Y. Kawakatsu, et al. 2020. "Resource Requirements for Essential Universal Health Coverage: A Modelling Study Based on Findings from Disease Control Priorities, $3^{\text {rd }}$ Edition". Lancet Global Health.

WHO. 2014. "Making Fair Choices on the Path to Universal Health Coverage". Bulletin of World Health Organization.

. 2019. Primary Health Care on the Road to Universal Health Coverage: 2019 Monitoring Report.

. 2020. "Responding to COVID-19_Learnings from Kerala".

WHO and World Bank. 2013. Monitoring Progress towards Universal Health Coverage at Country and Global Levels: A Framework.

-2019. Global Monitoring Report on Financial Protection in Health 2019.

WHO, World Bank, and OECD. 2018. Delivering Quality Health Services: A Global Imperative for Universal Health Coverage.

Winskill, P., C. Whittaker, P. Walker, et al. 2020. "Equity in Response to the COVID-19 Pandemic".

World Bank. 2018. World Development Report 2018: Learning to Realize Education's Promise.

- 2018b. 10 Years of Chile Grows with You: Key Components and Lessons Learned for the Setting Up of Comprehensive Child Development Support Systems.

. 2019. Ending Learning Poverty: What Will It Take?

—. 2019b. Human Capital Project: How Countries Nurture Human Capital - Implement a Whole of Government Approach; Coordination Across Government; Policies and Programs that Use and Expand the Evidence Base; Sustained Efforts Across Political Cycles.

2019c. High-Performance Health Financing for Universal Health Coverage: Driving Sustainable, Inclusive Growth in the 21st Century.

-. 2020. The Human Capital Index 2020 Update.

. 2020b. The COVID-19 Pandemic: Shocks to Education and Policy Responses.

=.2020c. Human Capital Project Case Studies Series.

- 2020d. Reimagining Human Connections: Technology and Innovation in Education at the World Bank.

CInternational Monetary Fund. Not for Redistribution 
- 2020e. Learning Poverty in The Time of Covid-19: A Crisis Within A Crisis.

-. 2020f. Realizing the Future of Learning: From Learning Poverty to Learning for Everyone, Everywhere.

Yamey, G., M. Schäferhoff, M. Pate, et al. 2020. "Funding the Development and Manufacturing of COVID-19 Vaccines". Duke Global WP 20. 